\title{
Recent Update on 1,3,4-Thiadiazole Derivatives: As Anticonvulsant Agents
}

\author{
Vinit Raj ${ }^{* 1}$, Amit Rai ${ }^{1}$, Mahendra Singh ${ }^{1}, \operatorname{Ram}_{\text {Kumar }}{ }^{1}$, Arvind Kumar $^{2}, \operatorname{Vinod~Kumar}^{3}$ \\ and S.K Sharma ${ }^{4}$ \\ ${ }^{1}$ Department of Pharmaceutical Sciences, Babasaheb Bhimrao Ambedkar University, Vidya Vihar, Rai Bareli Road, \\ Lucknow-226025, India. \\ ${ }^{2}$ Department of Pharmaceutical Chemistry (Pharmacy), S. D. College of Pharmacy and Vocational Studies, \\ Muzaffarnagar, U.P. India, Pin code-251001, India. \\ ${ }^{3}$ Member of Medical Research Unit Department of Physics, D. A. V. (P.G) College, \\ Muzaffarnagar, U.P, India, Pin Code -251001, India. \\ ${ }^{4}$ Department of Environmental Studies, University of Delhi -110007, India.
}

Abstract: 1,3,4-thiadiazole is one of the most potent heterocyclic containing carbonic anhydrase and antibacterial inhibitor from the natural and synthetic origin. It possessed potent anticonvulsant activity in wide range preclinical in vitro and in vivo models. Recently, various 1,3,4-thiadiazole derivatives have been synthesized and evaluated their anticonvulsant activity. This review is a demonstration to compile the medicinal chemistry, anticonvulsant screening and their structural activity relationship as well as pharmacophoric pattern of various synthesized 1,3,4-thiadiazole derivatives.

Key words: 1,3,4-thiadiazole, anticonvulsant, structure activity relationship and mechanism of action.

\section{INTRODUCTION}

In the last few years, heterocyclic compounds were not only used for development the heterocyclic derivatives, but also argumentation of the application in pharmaceutical and chemical field. Till date various heterocyclic compounds had been synthesized and evaluated for their significance. Firstly, Fischer was introduced 1,3,4thiadiazole in 1882, whereas Freund and Kuh were described the true nature of the ring. In addition, thiadiazole is a widespread and important five-member heterocyclic system which contains two nitrogen atoms and a sulfur atom. 1,2,3-thiadiazole, 1,2,4-thiadiazole, 1,2,5-thiadiazole, and 1,3,4-thiadiazole isomer of thiadiazole was discovered and evaluated for the biological activity.<smiles>c1csnn1</smiles>

1,2,3-Thiadiazole<smiles>c1ncsn1</smiles>

1,2,4-Thiadiazole<smiles>c1cnsn1</smiles>

1,2,5-Thiadiazole 1,3,4-Thiadiazole

Fig1. Structural formulae of isomers of thiadiazole

As per previous literature survey indicated that 1,3,4-thiadiazole have been most promised isomer than the other. Due to the sulfur atom of 1,3,4-thiadiazole ring produced the inductive effect, in this way shown very weak base property and possesses relatively high aromaticity[1-3].

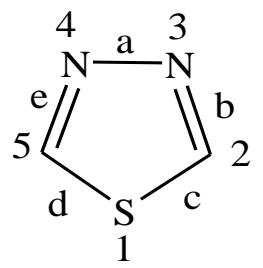

Fig2. Numbering of the 1,3,4-thiadiazole ring system

\footnotetext{
${ }^{1}$ Corresponding Author: raj.vinit24@gmail.com
} 
In addition, the nitrogen atoms of 1,3,4-thiadiazole ring is also shown to be very electron underprovided due to the electron-withdrawing effect and comparatively still toward electrophilic substitution, but susceptible to nucleophilic attack. Thus, possessing the substitution into the $2^{\prime}$ or a $5^{\prime}$ position of this ring and these substitutions involves highly activating reaction.

Till date many 1,3,4-thiadiazole nucleus containing drugs are available in the market such as acetazolamide, methazolamide, megazol and whereas 1,2,4-thiadiazole ring containing drug is the antibiotic cefozopram [4,5].<smiles>CC(=O)Nc1nnc(S(N)(=O)=O)s1</smiles>

Acetazolamide<smiles>CC(=O)NC1SC(S(N)(=O)=O)=NN1C</smiles>

Methazolamide<smiles>Cn1c([N+](=O)[O-])cnc1-c1nnc(N)s1</smiles>

Megazol

Fig3. Structural formula of 1,3,4-thiadiazole containing marketed drugs

Among their isomer, particularly the 1,3,4-thiadiazoles possessed a broad spectrum of biological activities including antimicrobial,[6] antituberculosis,[7] antioxidant,[8] anti-inflammatory,[9] anticonvulsants,[10] antidepressant and anxiolytic,[11] antihypertensive,[12] anticancer [13] and antifungal activity[14].

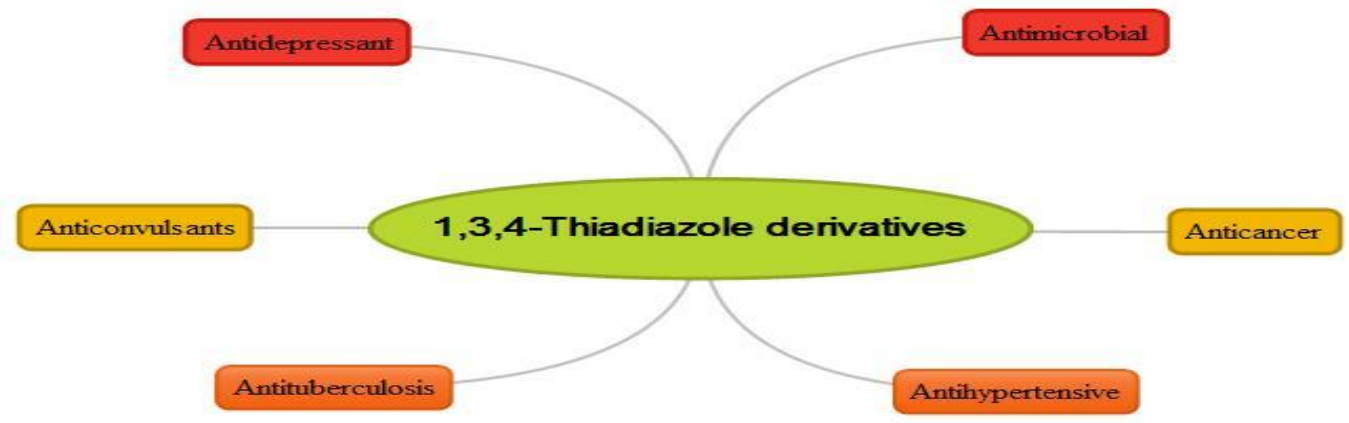

Fig4. Biological activity of 1,3,4-thiadiazole derivatoves

In this review, We give an overview to synthesis as well as the structure activity relationship of 1,3,4-thiadiazole derivatives. On the basis of the literature survey of cited references 1,3,4-thiadiazole ring contain compound shown the medicinal importance to treatment the epileptic condition.

\section{MECHANISM OF ACTION OF 1,3,4-THIADIAZOLE}

Till date various molecular target had been investigated for the treatment of epilepsy as following

\subsection{Nonsynaptic mechanisms}

$>$ Alterations in ionic microenvironment; e.g., increased extracellular $\mathrm{K}^{+}$, decreased extracellular $\mathrm{Ca}^{++}$

$>$ Decreases in size of extracellular space

$>$ Failure of ion transport: $\mathrm{Na}^{+}, \mathrm{K}^{+}$pump or $\mathrm{Cl}^{-}, \mathrm{K}^{+}$co-transport

$>$ Presynaptic terminal bursting

$>$ Ephaptic interactions

\subsection{Synaptic mechanisms}

$>$ 1. Depression of GABA-ergic inhibition

$>$ 2. NMDA receptor activation; voltage-dependent EPSPs

$>$ 3. Frequency potentiation of EPSPs

$>$ 4. Actions of modulators 


\section{American Research Journal of Pharmacy, Volume 1, Issue 1, 2015}

ISSN 2380-5706

These molecular targets related to blockage of voltage-dependent sodium channels to inhibit release of excitatory neurotransmitters, enhanced GABA-ergic transmission, inhibition of T-type calcium channels or kainite/AMPA receptors and a combination of the above actions [2].

Another approach has been identified in 1952. In which, 1,3,4-thiadiazole containing acetazolamide AZA targets carbonic anhydrase, in the brain has a significant role in the neurone-glia metabolic relationship. Carbonic anhydrase acted on the seizure by the mechanism that CAs catalyzes interconversion of $\mathrm{CO}_{2}$ and $\mathrm{HCO}_{3}$ the latter of which combines with hydrogen exchange across the glial membrane for sodium and chloride as well as contributed the current through the $\gamma$-amino butyrate A (GABAA) receptors. CAs are also involved in the maintenance of $\mathrm{Cl}^{-}$and $\mathrm{K}^{+}$concentrations in glial cells $[15,16,17]$.

\subsection{Essential Pharmacophore for anticonvulsant activity}

A pharmacophore based approach is one of the few applicable tools in modern drug design. Which is essential to develop new ligands with high affinity of binding to a given protein receptor. Whereas, this is the 3D arrangement of features in the biologically active compound that is responsible for its against a particular protein target. On the facts, if the 3D structure is available for several ligands bound to the same binding site of the same protein and in this way, observing their common arrangement of ligands into the binding site of a protein, referred to as the pharmacophore. Thiadiazole ring expressed diverse biological activities, might be due to the presence of $=\mathrm{N}-\mathrm{C}-\mathrm{S}$ moiety [18].

S. N. Pandeya [19] proposed that the following features are important for anticonvulsant activity.

$>$ Hydrophobic aryl ring (Ar),

$>$ A hydrogen bonding domain (HBD),

$>$ An electron-donor group (D) and

$>$ Another distal hydrophobic site

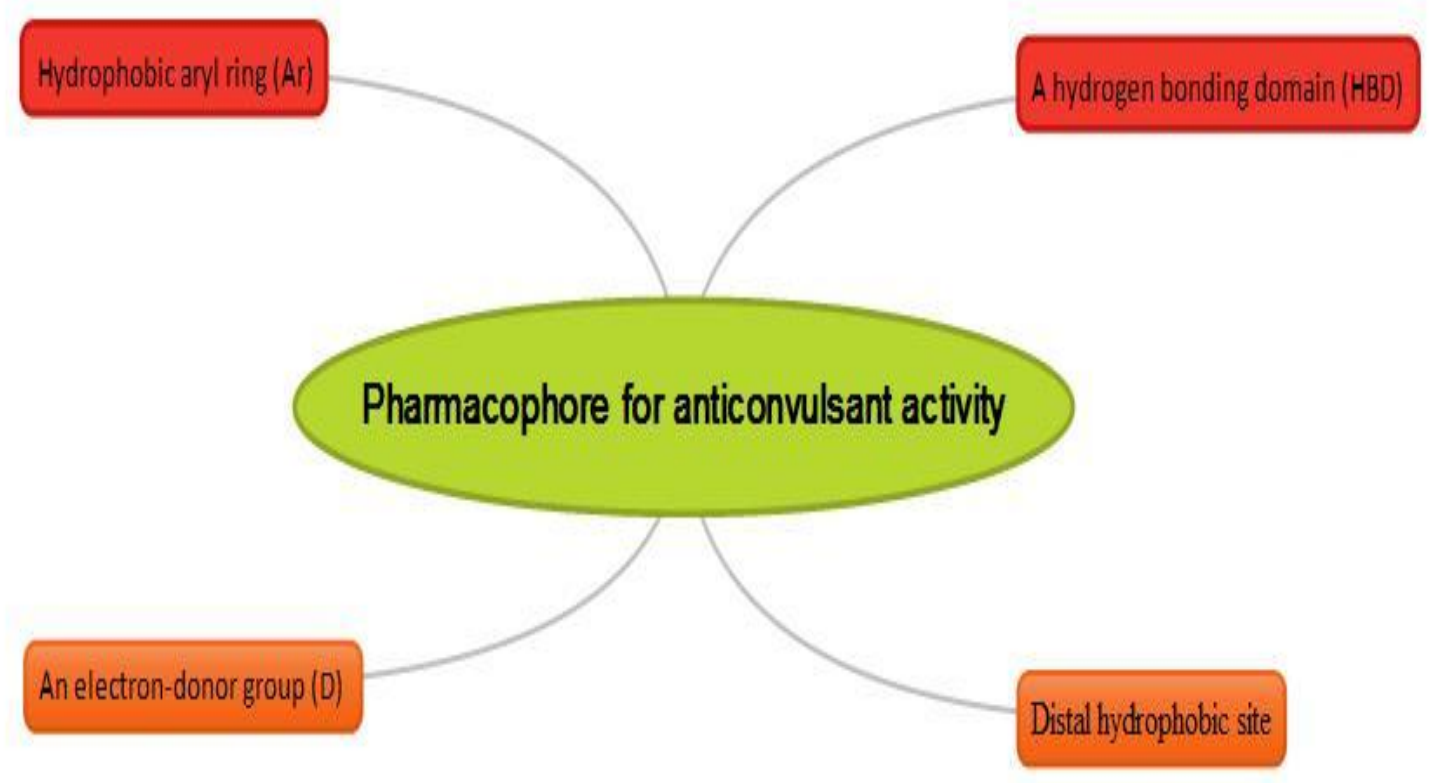

Fig5. Essential pharmacophoric requirements for anticonvulsant activity 
American Research Journal of Pharmacy, Volume 1, Issue 1, 2015

ISSN 2380-5706

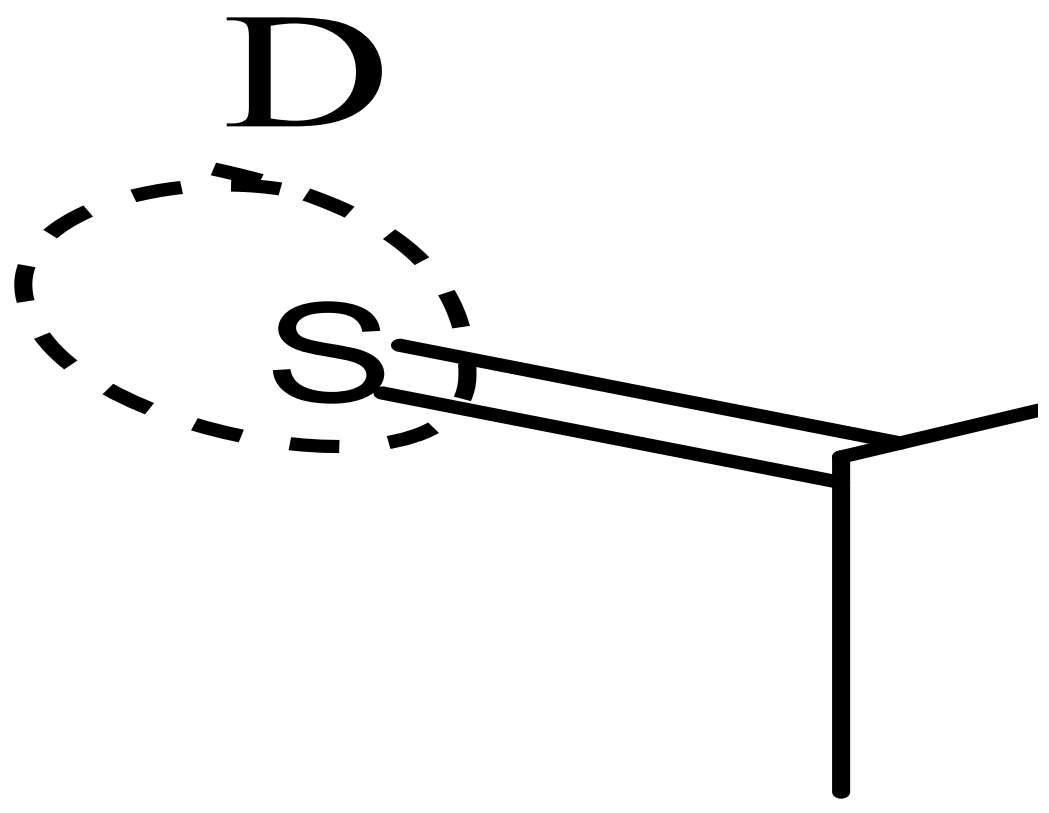


Fig6. Pharmacophoric pattern of well-known antiepileptic drugs

\subsection{Review literature of 1,3,4-thiadiazole derivatives as an anticonvulsant}

Christopher B. Chapleo et al. (1986) [20] synthesized a series of 2-aryl-5-hydrazino-1,3,4-thiadiazole derivatives and evaluated them for anticonvulsant activity. Among them, $\mathrm{N}$-methylhydrazine $\mathbf{1}$ shown potent anticonvulsant activity in rodent models of grand mal epilepsy and it has neither produced neurotoxicity nor cardiovascular actions occur at anticonvulsant doses.

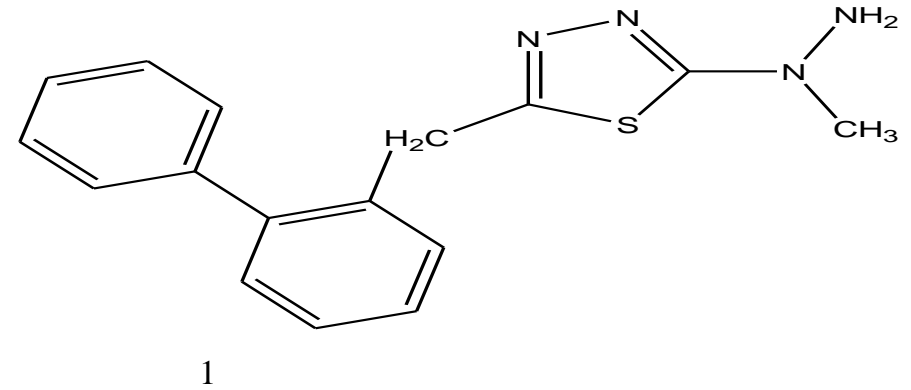

Fig8. Structure formulae of 2-aryl-5-hydrazino-l,3,4-thiadiazole derivatives

The SAR study of synthesized compounds reveals that the introduction of aromatic substituted in the 2-position tied with alkyl on the hydrazine moiety led to a number of potent compounds lacking sedation, ataxia, or lethality like as 5-(2-Biphenylyl)-2-(1-methylhydrazino)-1,3,4-thiadiazole (1).

\section{(a) Unsubsituted Compounds}

Substituent in the 2-position of the aromatic ring produced compounds (i.e., 2-6) shown desirable anticonvulsant activity with significantly reduced neurotoxicity in comparison to the $2-\mathrm{CH}_{3}$ compound 2 and replacement of the 2phenyl group (4) by a 4-phenyl (6) shown a complete loss of activity.<smiles>[R]c1cccc(-c2nnc(NN)s2)c1</smiles> 
American Research Journal of Pharmacy, Volume 1, Issue 1, 2015

ISSN 2380-5706

\begin{tabular}{|l|l|}
\hline Compounds & R \\
\hline 2 & $-2-\mathrm{CH}_{3}$ \\
\hline 3 & $2-\mathrm{Cl}$ \\
\hline 4 & $2-\mathrm{Ph}$ \\
\hline 5 & $2-\mathrm{C}_{6} \mathrm{H}_{13} \mathrm{O}$ \\
\hline 6 & $4-\mathrm{Ph}$ \\
\hline
\end{tabular}

Fig9. Structure formulae of unsubstituted thiadiazole derrivatives

\section{(b) N'-Monosubstituted Compounds}

The one side substitution at $\mathrm{N}_{1}$ in the 2-chloro and 2-phenyl series resulted in a decrease or loss of activity (i.e., $\mathrm{CH}_{3}$, i-Pr, n-Bu, $\mathrm{Ph}, \mathrm{CH}_{2} \mathrm{Ph}, \mathrm{CH}_{2} \mathrm{CH}_{2} \mathrm{Ph}$, cyclohexyl). One except benzyl derivative, which possessed a good profile of activity the ether containing group $\mathrm{CH}_{2} \mathrm{OCH}_{3}$, in place of $\mathrm{CH}_{3}$ would enhance the activity. The methylhydrazines had shown the most potent anticonvulsant activity in this series, especially the benzyl (7), 2-phenyl (8), and 2hexyloxy (9) derivatives, although the latter produced sedation as observed in the rotorod screen.

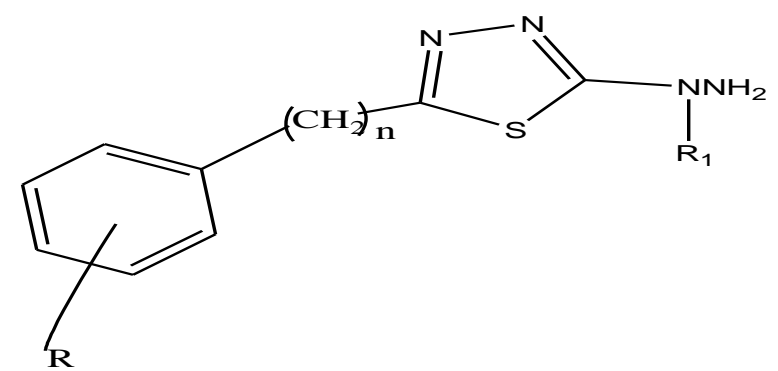

\begin{tabular}{|l|l|l|l|}
\hline Compounds & $\mathbf{R}$ & $\mathbf{R}_{\mathbf{1}}$ & $\mathbf{n}$ \\
\hline 7 & $\mathrm{H}$ & $\mathrm{CH}_{3}$ & 1 \\
\hline 8 & $2-\mathrm{Ph}$ & $\mathrm{CH}_{3}$ & 0 \\
\hline 9 & $2-\mathrm{C}_{6} \mathrm{H}_{13} \mathrm{O}$ & $\mathrm{CH}_{3}$ & 0 \\
\hline
\end{tabular}

Fig10. Structure formulae of mono substituted thiadiazole derrivatives

\section{(c) N2-Monosubstituted Compounds}

The isopropyl derivatives 10, 11 and $\mathbf{1 2}$ shown significant anticonvulsant activity; loss of activity observed when introduces 2-hexyloxy substitution in the $\mathbf{1 3}$ compound. Unexpectedly, the methyl derivative $\mathbf{1 4}$ was shown the loss of anticonvulsant activity in the 2- $\mathrm{CH}$, series and retained some of the antihypertensive activity. From the above suggestion, that better activity could be expected if the isopropyl group was replaced by cyclopentyl or benzyl groups.

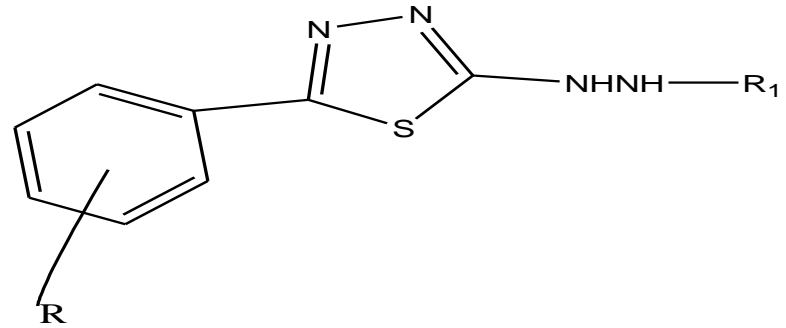

\begin{tabular}{|l|l|l|}
\hline Compounds & $\mathbf{R}$ & $\mathbf{R}$ \\
\hline 10 & $2-\mathrm{CH}_{3}$ & i-Pr \\
\hline 11 & $2-\mathrm{Cl}$ & i-Pr \\
\hline 12 & $2-\mathrm{Ph}$ & i-Pr \\
\hline 13 & $2-\mathrm{C}_{6} \mathrm{H}_{13} \mathrm{O}$ & i-Pr \\
\hline 14 & $2-\mathrm{CH}_{3}$ & $\mathrm{CH}_{3}$ \\
\hline
\end{tabular}

Fig11. Structure formulae of $\mathrm{N}_{2}$-Monosubstituted thiadiazole derivatives 


\section{(d) N', N2-Disubstituted Compounds}

Potent anticonvulsant activity was produced when the disubstitution with lower alkyl groups in the 2- $\mathrm{CH}_{3}$ and 2-C1 series compounds. Although, in the 2-phenyl and 2-hexyloxy series (i.e., 14-17) the potency was somewhat reduced and sedation was not apparent. The position of the isopropyl group in attached to $\mathbf{N 2}$, shown the activity in the following compounds $\mathbf{1 5}, \mathbf{1 6}, \mathbf{1 8}, \mathbf{1 9}$, and excepted then $\mathbf{2 0}, \mathbf{2 1}$. When the isopropyl group was replaced by the more lipophilic cyclopentyl group (i.e, $\mathbf{2 2}$ and $\mathbf{2 3}$ ), then the activity was reduced.

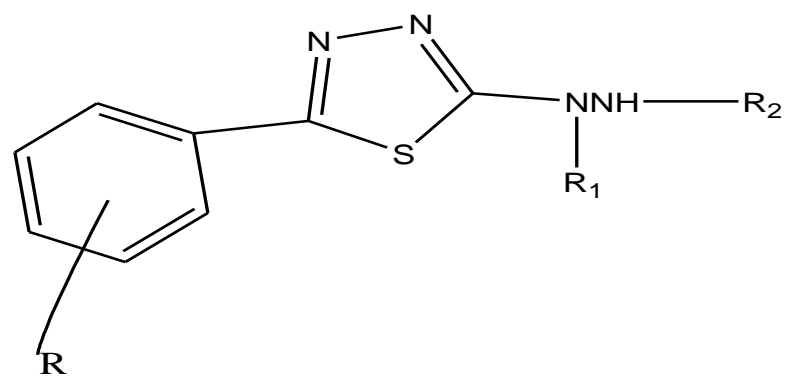

\begin{tabular}{|l|l|l|l|}
\hline Compounds & $\mathbf{R}$ & $\mathbf{R}_{\mathbf{1}}$ & $\mathbf{R}_{\mathbf{2}}$ \\
\hline 15 & $2-\mathrm{Ph}$ & $\mathrm{CH}_{3}$ & $i-\mathrm{Pr}$ \\
\hline 16 & $2-\mathrm{C}_{6} \mathrm{H}_{13} \mathrm{O}$ & $\mathrm{CH}_{3}$ & $\mathrm{CH}_{3}$ \\
\hline 17 & $2-\mathrm{C}_{6} \mathrm{H}_{13} \mathrm{O}$ & $\mathrm{CH}_{3}$ & $i-\mathrm{Pr}$ \\
\hline 18 & $2-\mathrm{CH}_{3}$ & $\mathrm{CH}_{3}$ & $i-\mathrm{Pr}$ \\
\hline 19 & $2-\mathrm{Cl}$ & $\mathrm{CH}_{3}$ & $i-\mathrm{Pr}$ \\
\hline 20 & $2-\mathrm{CH}_{3}$ & $i-\mathrm{Pr}$ & $\mathrm{CH}_{3}$ \\
\hline 21 & $2-\mathrm{Cl}$ & $i-\mathrm{Pr}$ & $\mathrm{CH}_{3}$ \\
\hline 22 & $2-\mathrm{CH}_{3}$ & $\mathrm{CH}_{3}$ & $c-\mathrm{C}_{5} \mathrm{H}_{9}$ \\
\hline 23 & $2-\mathrm{Cl}$ & $\mathrm{CH}_{3}$ & $c-\mathrm{C}_{5} \mathrm{H}_{9}$ \\
\hline
\end{tabular}

Fig12. Structure formulae of $N^{\prime}$, N2-Disubstituted thiadiazole derivatives

\section{(e) N2-Disubstitution}

Reduction in activity was found when disubstitution on the terminal nitrogen atom with the respective $\mathrm{CH}_{3}$-series.

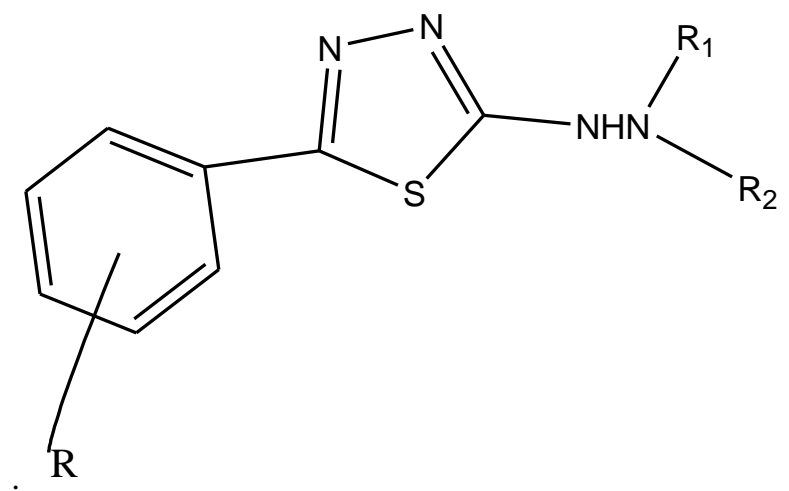

\begin{tabular}{|l|l|l|l|}
\hline Compounds & $\mathbf{R}$ & $\mathbf{R}_{\mathbf{1}}$ & $\mathbf{R}_{\mathbf{2}}$ \\
\hline 24 & $2-\mathrm{CH}_{3}$ & $\mathrm{CH}_{3}$ & $\mathrm{CH}_{3}$ \\
\hline 25 & $2-\mathrm{CH}_{3}$ & $\mathrm{CH}_{3}$ & $i$-Pr \\
\hline
\end{tabular}

Fig13. Structure formulae of N2-Disubstitution thiadiazole derivatives

\section{(f) Trisubstitution}

It was observed that the trimethylated derivatives $\mathbf{2 6 , 2 7}$ and $\mathbf{2 8}$ have somewhat anticonvulsant activity compared than other compounds of this series. Substitution of the methyl group on N' by larger groups considerably reduced this activity as seen with $\mathbf{2 9}$ and $\mathbf{3 0}$. Among of all the hydrazines examined, the most promising profile of activity is found in compounds based on the 2-Ph series. 


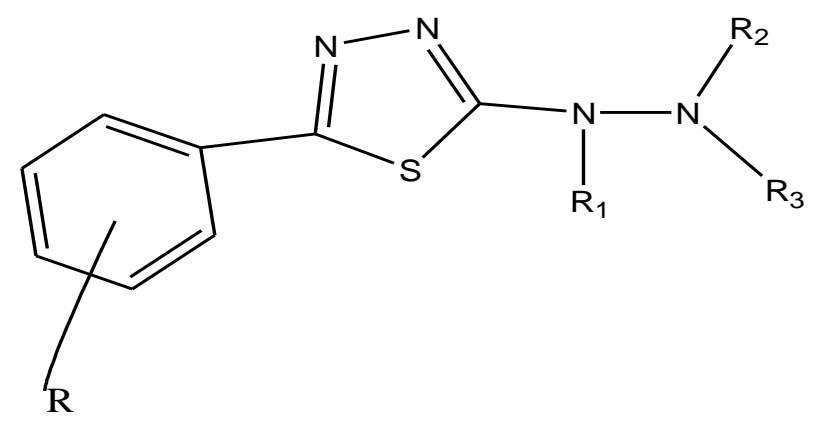

\begin{tabular}{|l|l|l|l|l|}
\hline Compounds & $\mathbf{R}$ & $\mathbf{R}_{\mathbf{1}}$ & $\mathbf{R}_{\mathbf{2}}$ & $\mathbf{R}_{\mathbf{3}}$ \\
\hline 26 & $2-\mathrm{CH}_{3}$ & $\mathrm{CH}_{3}$ & $\mathrm{CH}_{3}$ & $\mathrm{CH}_{3}$ \\
\hline 27 & $2-\mathrm{CH}_{3}$ & $\mathrm{PhCH}_{3}$ & $\mathrm{CH}_{3}$ & $\mathrm{CH}_{3}$ \\
\hline 28 & $2-\mathrm{Cl}$ & $\mathrm{CH}_{3}$ & $\mathrm{CH}_{3}$ & $\mathrm{CH}_{3}$ \\
\hline 29 & $2-\mathrm{Cl}$ & $i-\mathrm{Pr}$ & $\mathrm{CH}_{3}$ & $\mathrm{CH}_{3}$ \\
\hline 30 & $2-\mathrm{CH}_{3}$ & $\mathrm{CH}_{3}$ & $\mathrm{CH}_{3}$ & $\mathrm{CH}_{3}$ \\
\hline
\end{tabular}

Fig14. Structure formulae of Trisubstitution thiadiazole derivatives

Michael R. Stillings et al.(1986) [21] synthesized a series of substituted 1,3,4-thiadiazoles derivatives and evaluated for the anticonvulsant activity. Among them, the most potent 2-(aminomethyl)-5-(2-biphenylyl)-1, 3, 4-thiadiazole (31) compound showed anticonvulsant activity in both rats and mice and compared with the standard anticonvulsant drugs phenytoin, phenobarbital, and carbamazepine. This compound was produced 6.5 protective index $(\mathrm{PI})\left(\mathrm{TD}_{50}\right.$ divided by $\mathrm{ED}_{50}$ i.p. at time of peak effect) as the compared phenytoin, phenobarbital, and carbamazepine were 7, 4.8 , and 11 , respectively.

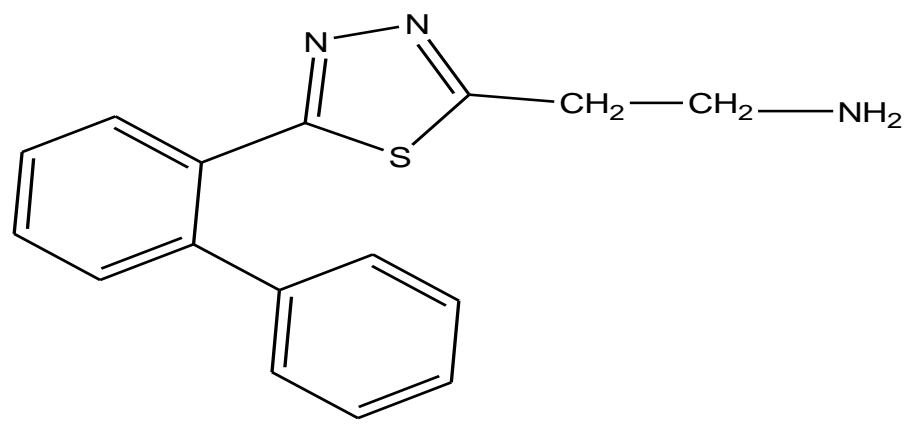

31

Fig15. Structure formulae of 1,3,4-thiadiazole derivatives

SAR study of the synthesized compounds reveals that the introduction of alkylation of the side-chain nitrogen atom produced the potent compound. However, aryl substitution or chain lengthening decrease the activity. Replacement of 2-biphenylyl group by phenyl or benzyl caused loss of anticonvulsant activity. Whereas, the n-propylamino derivative (32) was devoid of anticonvulsant activity. The branched-chain substitution of derivative (33) still retained significant activity. Further introduction of aryl group in compound $\mathbf{3 4}$ and another 2-biphenylyl group of substitution in the phenyl (35) and benzyl (36) derivatives shown the lack of another approach was found if the 2phenyl group into the benzyl derivative to give the biphenylylmethylene compound (19) caused a marked increase in activity. Introduction of the 2-biphenylyl moiety in compounds 16 and 17, which showed some anticonvulsant activity.<smiles>[R]c1nnc(C([R])C)s1</smiles> 
American Research Journal of Pharmacy, Volume 1, Issue 1, 2015

ISSN 2380-5706

\begin{tabular}{|c|c|c|c|c|c|}
\hline Compounds & $\mathbf{R}$ & $\mathbf{R}_{1}$ & $\mathbf{R}_{2}$ & $\mathbf{R}_{\mathbf{3}}$ & $\mathbf{n}$ \\
\hline 32 & & $\mathrm{H}$ & $\mathrm{H}$ & $\mathrm{CH} 3$ & 0 \\
\hline 33 & $\mathrm{Ph}$ & $\mathrm{H}$ & $\mathrm{H}$ & $\mathrm{H}$ & 2 \\
\hline 34 & Ph & $\mathrm{CH} 3$ & $\mathrm{H}$ & $\mathrm{H}$ & 0 \\
\hline 35 & & $\mathrm{H}$ & $\mathrm{H}$ & & 0 \\
\hline 36 & & $\mathrm{H}$ & $\mathrm{H}$ & $\mathrm{H}$ & 0 \\
\hline 37 & & $\mathrm{H}$ & $\mathrm{H}$ & $\mathrm{CH} 3$ & 0 \\
\hline 38 & & $\mathrm{H}$ & $\mathrm{H}$ & $\mathrm{H}$ & 0 \\
\hline 39 & & $\mathrm{H}$ & $\mathrm{H}$ & $\mathrm{H}$ & 0 \\
\hline
\end{tabular}

Fig16. Structure formulae of Substituted 1,3,4-Thiadiazoles

Christopher B. Couple et al. (1987) [22] synthesized a series of 2-aryl-5-guanidino-1,3,4-thiadaizole derivatives and screened them for anticonvulsant activity. Among them unsubstituted guanidine (40) showed potent anticonvulsant activity in the rat MES model and the level of neurotoxicity shown in acceptable range.

SAR study of synthesized compounds reveals that $\mathbf{4 0}$ is the most potent anticonvulsant agent than the other compounds of this series. Considerable of substituted guanidines is an essential key to the reduction or loss of activity of synthesized derivatives. Internalization of the guanidine group into an imidazoline ring also resulted in a 
loss of activity. However, with the exception of methylated derivative 41, the terminal of methyl group with the substituted guanidines were found to reduction or complete loss of activity and the guanidine grouping into an imidazoline ring also devoid of anticonvulsant activity.

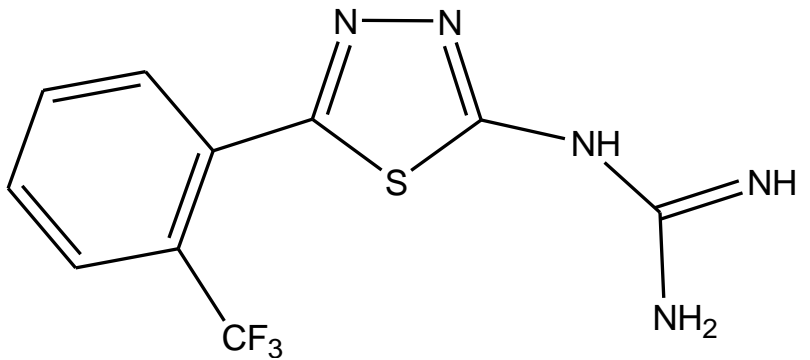

40

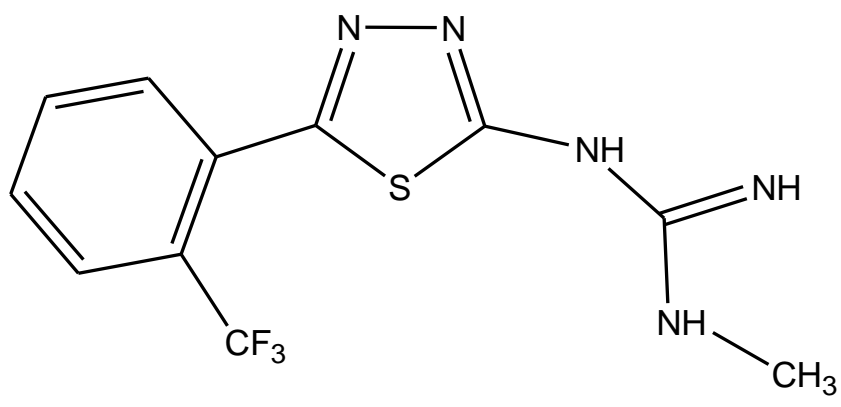

41

Fig17. Structure formulae of 2-aryl-5-guanidino-1,3,4-thiadaizole derivatives

Christopher B. Chapleo et al. (1988) [23] synthesized two novel series of 2-aryl-1, 3, 4-thiadiazole amidines and evaluated for anticonvulsant activity using by MES model. Among them the most potent $\mathbf{4 2}$ compound occurred in the 5-[2 (trifluoromethyl) phenyl] series, but the level of sedation was also high. Whenever, the 2-methyl series it was found that the N-buty analogue $\mathbf{4 3}$ possessed higher anticonvulsant activity and lesser neurotoxic effects than the parent amidine 44. The $\mathrm{N}$-substituted analogues 45-47 are also more significant effect in the MES test than 44, but less so than 43. However, in the 2-trifluoromethyl series, the parent amidine containing possessed slightly higher anticonvulsant activity than the N-butyl analogue, although both compounds possessed a similar level of neurotoxicity. A similar finding was observed in the 2-phenyl series 48-49 (MES test).

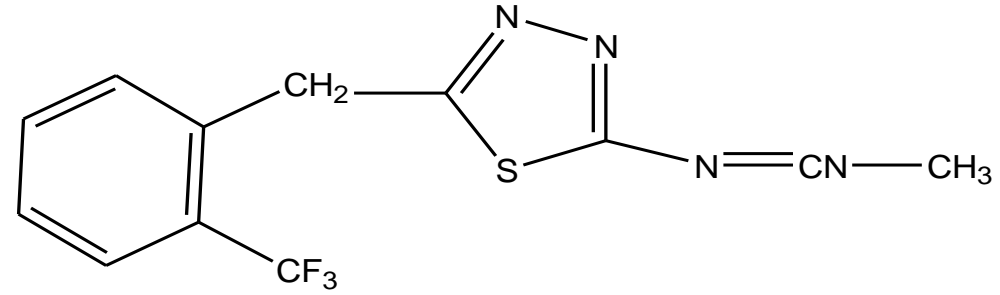

42

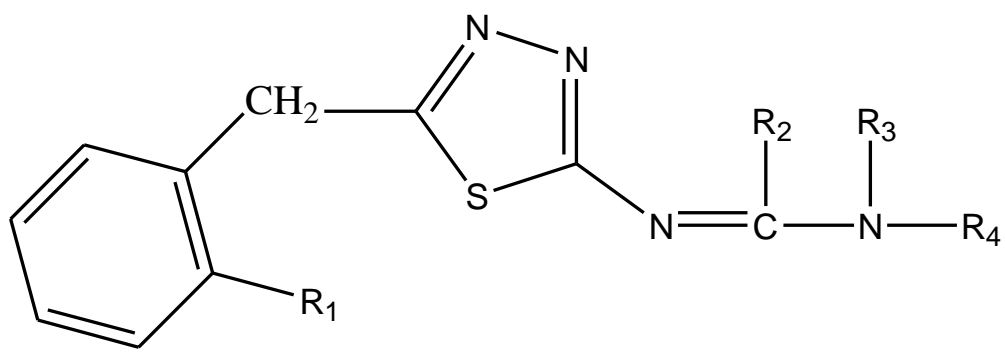


American Research Journal of Pharmacy, Volume 1, Issue 1, 2015

ISSN 2380-5706

\begin{tabular}{|c|c|c|c|c|c|}
\hline Compounds & $\mathbf{R}_{1}$ & $\mathbf{R}_{2}$ & $\mathbf{R}_{3}$ & $\mathbf{R}_{4}$ & n \\
\hline 43 & $\mathrm{CH}_{3}$ & $\mathrm{CH}_{3}$ & $\mathrm{nBu}$ & $\mathrm{H}$ & 0 \\
\hline 44 & $\mathrm{CH}_{3}$ & $\mathrm{CH}_{3}$ & $\mathrm{H}$ & $\mathrm{H}$ & 0 \\
\hline 45 & $\mathrm{CH}_{3}$ & $\mathrm{CH}_{3}$ & $\mathrm{Ph}$ & $\mathrm{H}$ & 0 \\
\hline 46 & $\mathrm{CH}_{3}$ & $\mathrm{CH}_{3}$ & $\mathrm{C}_{2} \mathrm{H}_{5}$ & $\mathrm{C}_{2} \mathrm{H}_{5}$ & 0 \\
\hline 47 & $\mathrm{CH}_{3}$ & $\mathrm{CH}_{3}$ & $\mathrm{CH}_{2}-\mathrm{C}$ & $\mathrm{C}_{2} \mathrm{H}_{5}$ & 0 \\
\hline 48 & $\mathrm{Ph}$ & $\mathrm{CH}_{3}$ & $\mathrm{H}$ & $\mathrm{H}$ & 0 \\
\hline 49 & $\mathrm{Ph}$ & $\mathrm{CH}_{3}$ & $\mathrm{nBu}$ & $\mathrm{H}$ & 0 \\
\hline
\end{tabular}

Fig18. Structure formulae of 2-aryl-1, 3, 4-thiadiazole amidines

H. N. Dogan et al. (2002) [24] synthesized two new series of 2,5-disubstituted-1,3,4-thiadiazoles derivatives and evaluated them for anticonvulsant activity. Among these compounds, 50 (90\%) and $\mathbf{5 1}(70 \%)$ showed maximum protection at a dose of $100 \mathrm{mg} / \mathrm{kg}$ ip against pentylenetetrazole-induced convulsions. The ED50 values of the most effective compounds, $\mathbf{5 0}$ and $\mathbf{5 1}$ were 33 and $66 \mathrm{mg} / \mathrm{kg}$, respectively. The lower dose $(50 \mathrm{mg} / \mathrm{kg})$ was ineffective (50: $50 \%$ and 51: $40 \%)$ and the higher dose $(150 \mathrm{mg} / \mathrm{kg}$ ) did not increase the efficiency (50: $90 \%$ and 51: $70 \%)$. Therefore the dose of $100 \mathrm{mg} / \mathrm{kg}$ was selected as the best one.<smiles>CCNc1nnc(-c2cc3ccccc3cc2O)s1</smiles>

50

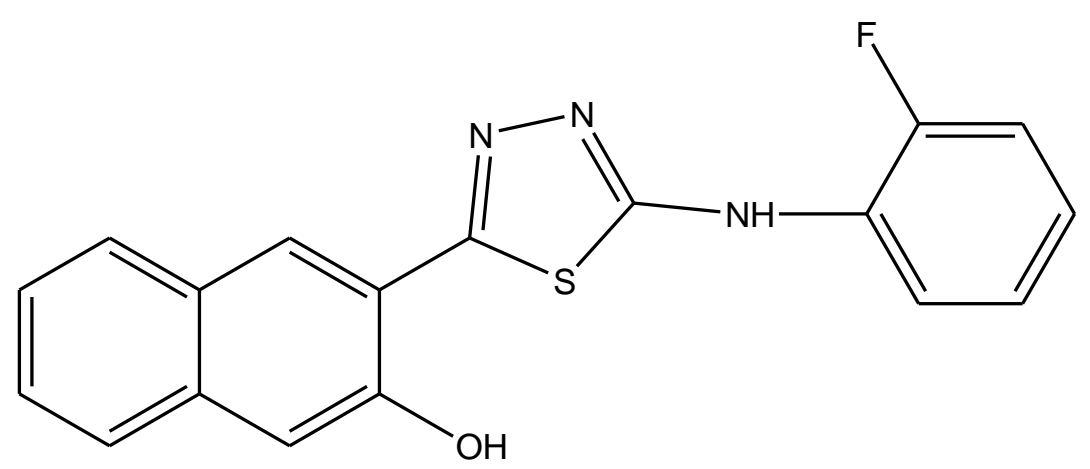

51

Fig19. Structure formulae of 2,5-disubstituted-1,3,4-thiadiazoles derivatives

Archanaet al. (2002)[25] synthesized a series of 3-\{[5-(alkylbenzylideneamino)-1,3,4-thiadiazol-2yl]methylamino\}2-methyl-6-monosubstituted quinazolin-4(3H)-one and evaluated them anticonvulsant activity using by in MES models and PTZ model also. Among them the most active compound was 3-(\{4-[2-(m-methoxy-phydroxyphenyl)-4oxo-1,3-thiazolidin-3-yl]-1,3,4-thiadiazol-2-yl\} methylamino)-2-methyl-6-bromo-quinazolin-4(3H)-one (52).

The SAR study of synthesized compounds reveals that the presence of a five-membered thiadiazole ring at the 3rd position of 3-amino-2-methyl-6-monosubstituted quinazolin-4(3H)-onyl moieties which were further substituted with alkyl benzylidenyl groups at the 2 nd position of five-membered thiadiazole ring are the essential for the anticonvulsant activity. Whenever, compounds having 3-amino-2-methyl-6-bromoquinazolin-4(3H)-onyl moiety 
showed more protection in comparison to compounds having 3-amino-2-methylquinazolin-4(3H) onyl moiety. It was observed that compounds having phenyl group and 3-methoxy-4-hydroxy phenyl ring produced the maximum percent protection (70 and $80 \%$, respectively) against seizures induced by MES. Compounds substituted with 4 methoxyphenyl group and 3-methoxyphenyl group exhibited 60 and 70\% inhibition of seizures, respectively. Compounds having 4-hydroxy phenyl group also elicited remarkable anticonvulsant activity. It may be concluded that substitution with 3-methoxy-4-hydroxyphenyl group is beneficial for anticonvulsant activity.

Further, the next step of the series was characterized by the presence substituted with 3-methoxy, 4-hydroxy phenyl group shown most potent activity of 80 and $90 \%$, respectively

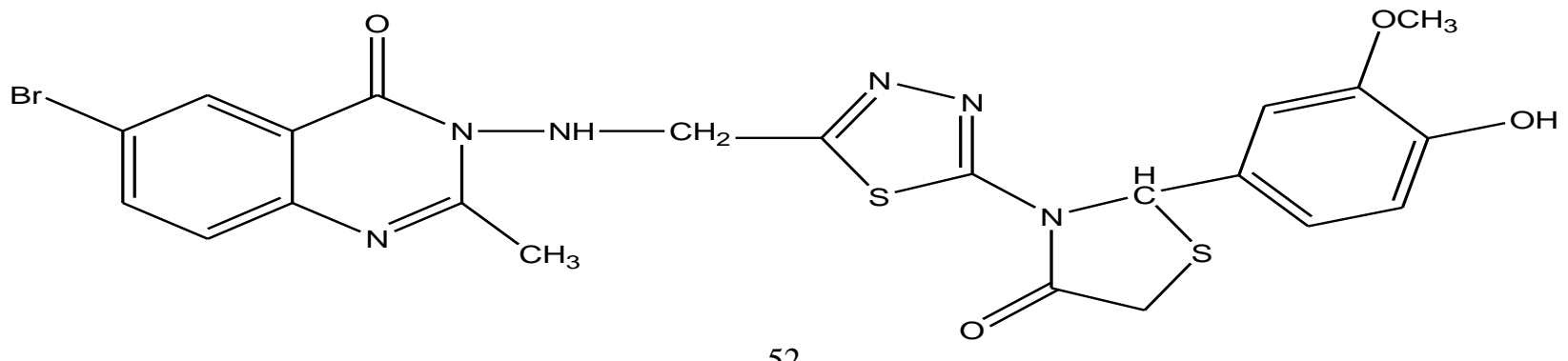

52

Fig20. Structure formulae of 3-\{[5-(alkylbenzylideneamino)-1,3,4-thiadiazol-2-yl]methylamino\}-2-methyl-6monosubstituted quinazolin-4(3H)-one

Hatice N. Dogan et al. (2002) [26] synthesized two new series of 2,5-disubstituted-1,3,4-thiadiazoles and evaluated them for anticonvulsant activity. Among them, compounds 53 (90\%) and 54 (70\%) showed maximum protection. The acetylation of thiadiazoles retained anticonvulsant effectiveness to a lesser degree. The ED50 values of these compounds were 33 and $66 \mathrm{mg} / \mathrm{kg}$, respectively. Therefore the dose of $100 \mathrm{mg} / \mathrm{kg}$ was selected as the best one.
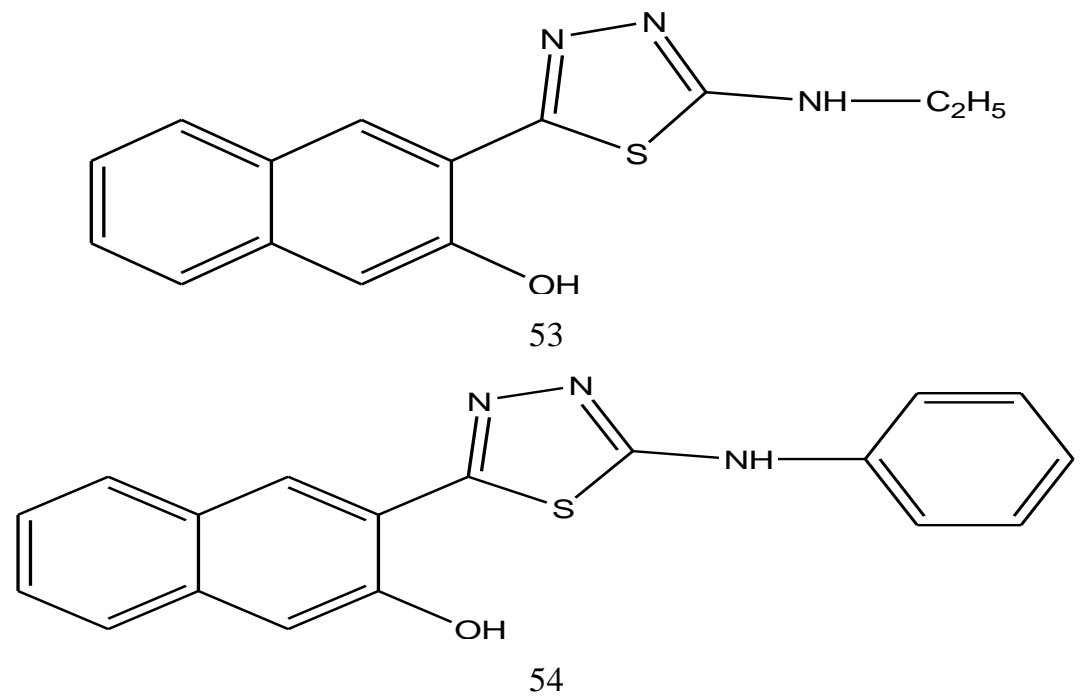

Fig21. Structure formulae of 2,5-disubstituted-1,3,4-thiadiazole

Archana et al. (2004)[27] synthesized a novel series of substituted quinazolinonyl-2-oxo/thiobarbituric acid and performed screened for their anticonvulsant activity in MES and PTZ models. Among them the most potent compound 66, showed activity (90\%) compared than the standard drug. Compounds 55-58 showed more potent activity (40-60\% in MES and 40-50\% in PTZ models). Whereas, compounds 59-66 produced good percentage protection ranging from 60 to $90 \%$ in both models (MES and PTZ). Among them, compound $\mathbf{6 6}$ is the most potent anticonvulsant compound which possess same percentage protection at lower doses of 17.5 and $25 \mathrm{mg} / \mathrm{kg}$ ip (20 and $40 \%$ protection in MES model, respectively) and different inhibition of seizures at a higher dose at $50 \mathrm{mg} / \mathrm{kg}$ ip (80 and $90 \%$ inhibition in MES model, respectively). This compound, in PTZ model in three graded doses was exhibited protection of $20,30,80 \%$ and $20,50,90 \%$, respectively. 
The SAR study of the synthesized compound reveals that the introduction dibromo group at the $6^{\text {th }}$ and $8^{\text {th }}$ positions of quinazolinone nucleus was found to increase the anticonvulsant activity. Whenever, cyclization of intermediate into corresponding thiadiazole was found to be fruitful as the presence of this five membered ring showed considerable increase in Percentage inhibition of seizures. Furthermore, incorporation of 2-oxo/thiobarbituric acid in 55-58 was found to increase the potency of these compounds and resulted into the formation of 59-66, respectively, with high anticonvulsant activity.

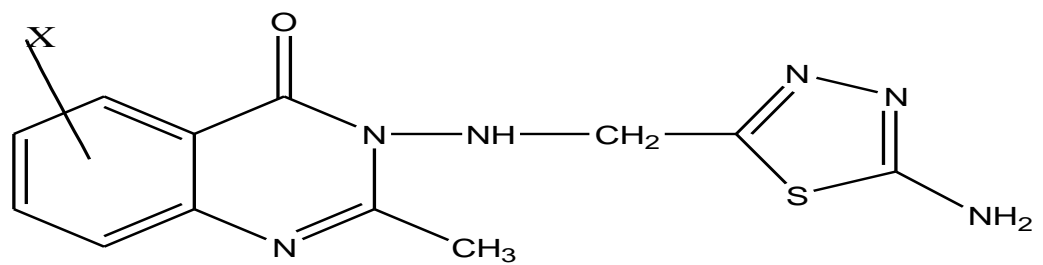

\begin{tabular}{|l|l|}
\hline Compounds & $\mathbf{X}$ \\
\hline 55 & $\mathrm{H}$ \\
\hline 56 & $6-\mathrm{I}$ \\
\hline 57 & $6-\mathrm{Br}$ \\
\hline 58 & $6,8-\mathrm{Br}_{2}$ \\
\hline
\end{tabular}

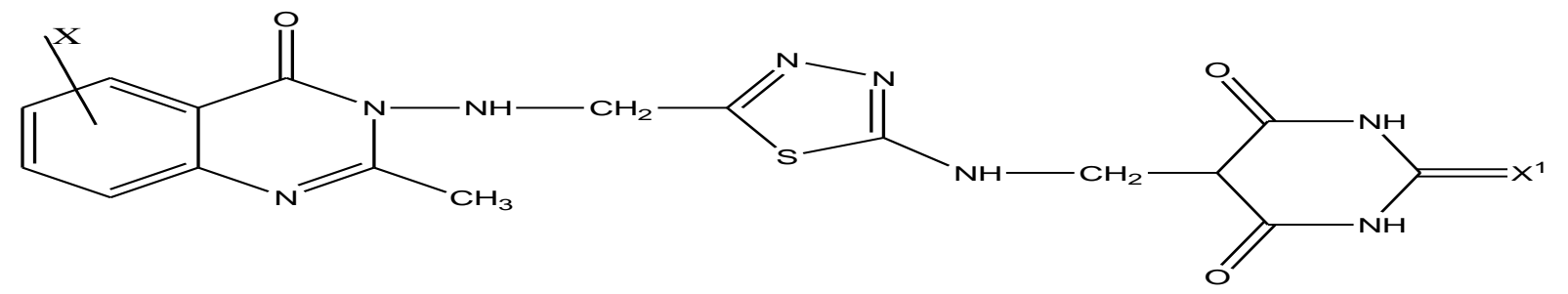

\begin{tabular}{|l|l|l|}
\hline Compound & $\mathbf{X}$ & $\mathbf{X}^{1}$ \\
\hline 59 & $\mathrm{H}$ & $\mathrm{O}$ \\
\hline 60 & $6-\mathrm{I}$ & $\mathrm{O}$ \\
\hline 61 & $6-\mathrm{Br}$ & $\mathrm{O}$ \\
\hline 62 & $6,8-\mathrm{Br} 2$ & $\mathrm{O}$ \\
\hline 63 & $\mathrm{H}$ & $\mathrm{S}$ \\
\hline 64 & $6-\mathrm{I}$ & $\mathrm{S}$ \\
\hline 65 & $6-\mathrm{Br}$ & $\mathrm{S}$ \\
\hline 66 & $6,8-\mathrm{Br} 2$ & $\mathrm{~S}$ \\
\hline
\end{tabular}

Fig22. Structure formulae of substituted quinazolinonyl-2-oxo/thiobarbituric acid

M. A. Ilies et al.(2004) [28] synthesized a series of aromatic/heterocyclic sulfonamides incorporating adamantyl moieties and evaluated for the anticonvulsant activity using by a MES test in mice. After intraperitoneal injection (30 mg kg${ }^{1}$ ), among them compound $\mathbf{6 7}$ exhibited a high protection against electrically induced convulsions at a dosage of: $20,10,5$ and $2.5 \mathrm{mg} / \mathrm{kg}$. (>90\%). Their ED50 was $3.5 \mathrm{mg} \mathrm{kg}^{-1}$.

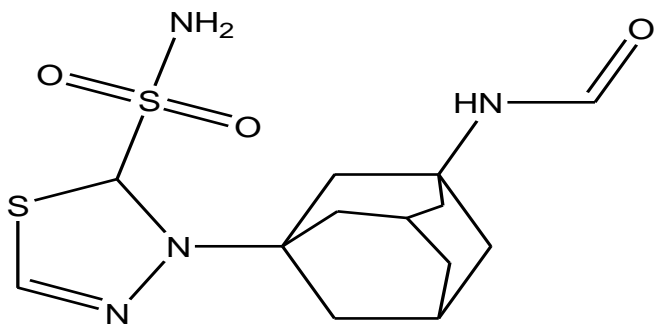

67

Fig23. Structure formulae of 5-(Adamantan-1-yl-carboximido)-4-methyl-4 ${ }^{2}$-1,3,4-thidiazoline-2-sulfonamide 
K. M. Dawood et al. (2006) [29] synthesized newly benzotriazole derivatives and screened them for anticonvulsant activity in maximal electroshock seizure (MES) and subcutaneous metrazole (ScMet) test in mice. Among them compounds 68 and 69 were found to be active in ScMet only, whereas the test compounds 70 was active in MES.

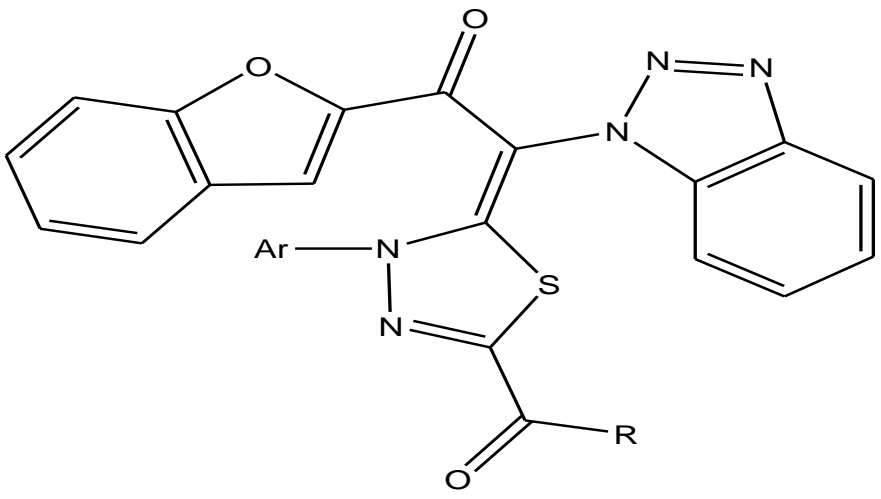

\begin{tabular}{|l|l|l|}
\hline Compound & $\mathbf{R}$ & $\mathbf{A r}$ \\
\hline $\mathbf{6 8}$ & $\mathrm{CH}_{3}$ & $\mathrm{C}_{2} \mathrm{H}_{5}$ \\
\hline $\mathbf{6 9}$ & $\mathrm{OC}_{2} \mathrm{H}_{5}$ & $\mathrm{C}_{6} \mathrm{H}_{5}$ \\
\hline $\mathbf{7 0}$ & $\mathrm{OC}_{2} \mathrm{H}_{5}$ & $4-\mathrm{MeC}_{6} \mathrm{H}_{4}$ \\
\hline
\end{tabular}

Fig24. Structure formulae of benzotriazole derivatives

Foroumadi A et al. (2007) [30] synthesized a series of a novel 2-amino-5-[4-chloro-2-(2-chloro phenoxy)phenyl]1,3,4-thiadiazole derivatives and evaluated for their anticonvulsant activity by a lethal doses of pentylentetrazole (PTZ) and maximal electroshock (MES). Among them the synthesized compounds, 5-[4-chloro-2-(2chlorophenoxy)phenyl]- $N$-ethyl-1,3,4-thiadiazol-2-amine $\mathbf{7 1}$ was the most active compound in both MES and PTZ tests with an $\mathrm{ED}_{50}$ of 20.11 and $35.33 \mathrm{mg} / \mathrm{kg}$, respectively. Whereas, Compound 5-(4-chloro-2-(2-chlorophenoxy) phenyl)-N-ethyl-1,3,4-thiadia-zol-2-amine 72 was the most active compound in both MES (ED $=20.11$ ) and PTZ $\left(\mathrm{ED}_{50}=35.33\right)$ tests.

The SAR study of synthesized compounds reveals that the introduction of unsubstituted amino group exerted inactive in both PTZ and MES tests. The replacement of the amino group with a methyl group led to slight increase in the activity of the compound in MES , as similar the presence of ethyl group increased the activity in both MES and PTZ. On the other hand, substitution of the amino group by a phenyl moiety produced inactive componds in both tests. These result concluded that in 2-amino-1,3,4-thiadiazoles substituted by a hydroxynaphthyl group at position 5, showed the higher protection.<smiles>Nc1nnc(-c2ccc(Cl)cc2Oc2ccccc2Cl)s1</smiles> 


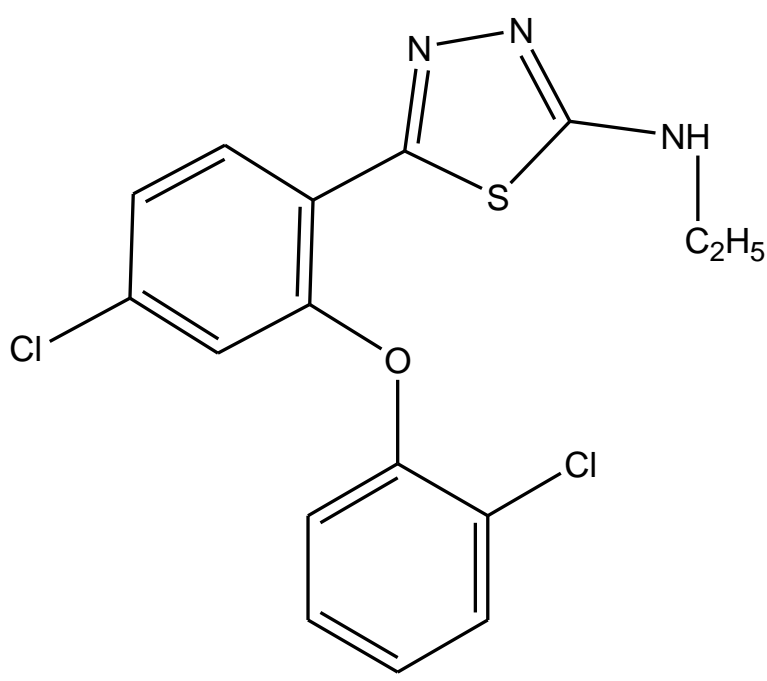

72

Fig25. Structure formulae of 2-amino-5-[4-chloro-2-(2-chlorophenoxy)phenyl]-1,3,4-thiadiazole

Sushil Kashaw et al. (2008) [31] synthesized a series of novel 3-[5-substituted phenyl-1,3,4-thiadiazole-2-yl]-2styryl quinazoline-4(3H)-ones derivatives and evaluated them for anticonvulsant activity employing two model (the maximal electroshock induced seizures (MES) and subcutaneous pentylenetetrazole (scPTZ) induced seizure

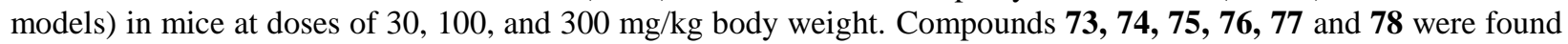
to exhibit anticonvulsant activity in MES screen, among of them, compound $\mathbf{7 3}$ showed potency similar to standard drug (phenytoin, carbamazepine) without any neurotoxicity. Whereas, compound $\mathbf{7 4}$ showed activity in the MES screen after $0.5 \mathrm{~h}(100 \mathrm{mg} / \mathrm{kg})$. This compound exhibited rapid onset of action and long duration of activity.

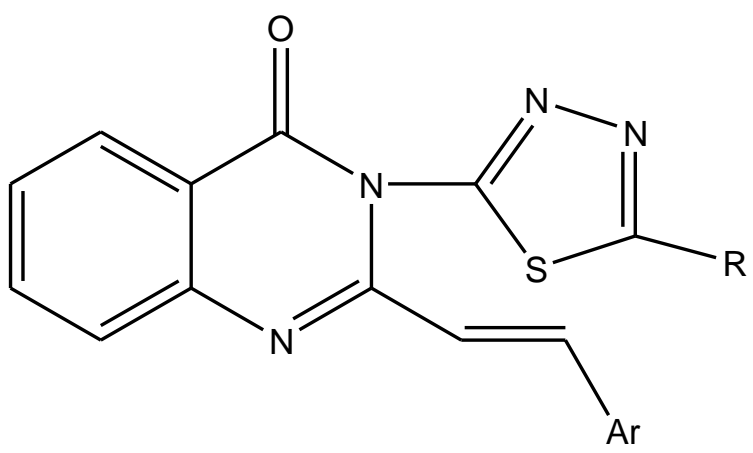

\begin{tabular}{|l|l|l|}
\hline Compound & Ar & R \\
\hline $\mathbf{7 3}$ & $\mathrm{C}_{6} \mathrm{H}_{5}$ & $\mathrm{C}_{6} \mathrm{H}_{5}$ \\
\hline $\mathbf{7 4}$ & $\mathrm{C}_{6} \mathrm{H}_{5}$ & $\mathrm{p}-\mathrm{ClC}_{6} \mathrm{H}_{5}$ \\
\hline $\mathbf{7 5}$ & $\mathrm{C}_{6} \mathrm{H}_{5}$ & $\mathrm{~m}-\mathrm{ClC}_{6} \mathrm{H}_{5}$ \\
\hline $\mathbf{7 6}$ & $\mathrm{p}-\mathrm{OCH}_{3} \mathrm{C}_{6} \mathrm{H}_{5}$ & $\mathrm{p}-\mathrm{OCH}_{3} \mathrm{C}_{6} \mathrm{H}_{5}$ \\
\hline $\mathbf{7 7}$ & $\mathrm{p}-\mathrm{OCH}_{3} \mathrm{C}_{6} \mathrm{H}_{5}$ & $\mathrm{~m}-\mathrm{ClC}_{6} \mathrm{H}_{5}$ \\
\hline $\mathbf{7 8}$ & $\mathrm{p}-\mathrm{CH}_{3} \mathrm{C}_{6} \mathrm{H}_{5}$ & $\mathrm{p}-\mathrm{ClC}_{6} \mathrm{H}_{5}$ \\
\hline
\end{tabular}

Fig26. Structure formulae of 3-[5-substituted phenyl-1,3,4-thiadiazole-2-yl]-2-styryl quinazoline-4(3H)-ones derivatives

Sushil Kashaw et al. (2008) [32]synthesized a new 3-[5-substituted phenyl-1,3,4-thiadiazole-2-yl]-2-styryl quinazoline-4(3H)-ones derivatives and screening them for anticonvulsant activity after i.p. injection doses 0.01 $\mathrm{ml} / \mathrm{g}$ body weight for mice or 30,100 , and $300 \mathrm{mg} / \mathrm{kg}$ body weight for rat and examined in the maximal electroshock (MES) induced seizures and subcutaneous pentylenetetrazole (scPTZ) induced seizure models in mice. Among them, compounds 79, 80 and $\mathbf{8 1}$ showed anticonvulsant activity in one or more test models. 


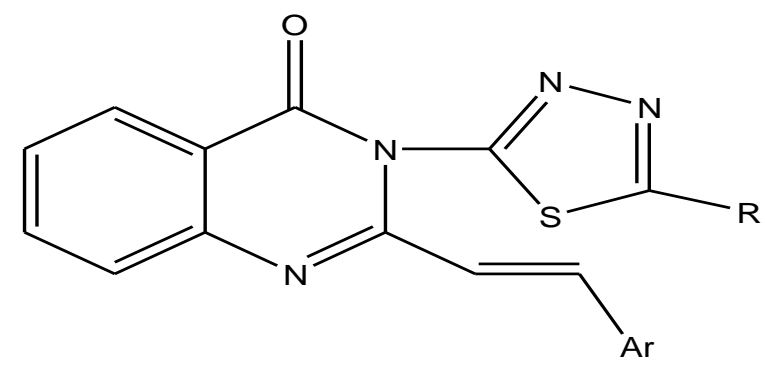

\begin{tabular}{|l|l|l|}
\hline Compounds & Ar & R \\
\hline $\mathbf{7 9}$ & $\mathrm{p}-\mathrm{ClC}_{6} \mathrm{H}_{4}$ & $\mathrm{C}_{6} \mathrm{H}_{5}$ \\
\hline $\mathbf{8 0}$ & $\mathrm{p}-\mathrm{ClC}_{6} \mathrm{H}_{4}$ & $\mathrm{~m}-\mathrm{ClC}_{6} \mathrm{H}_{4}$ \\
\hline $\mathbf{8 1}$ & & $\mathrm{p}-\mathrm{ClC}_{6} \mathrm{H}_{4}$ \\
& & \\
\hline
\end{tabular}

Fig27. Structure formulae of 3-[5-substituted phenyl-1,3,4-thiadiazole-2-yl]-2-styryl quinazoline-4(3H)-ones derivatives

Asif Husain et al.(2009)[33] synthesized a series of 3,6-disubstituted-1,2,4-triazolo-1,3,4-thiadiazole derivatives and evaluated for their anticonvulsant activity and neurotoxicity. In anti-MES activity compounds 82, 83, 84 and 86 showed potent activity comparable to that of standard drugs: phenytoin and carbamazepine. Compound $\mathbf{8 4}$ successfully passed the rotorod test without any sign of neurological deficit.

SAR study of the synthesized compounds reveals that the halosubstituted aryl (bromophenyl) in position 6 of the triazolothiadiazole ring was essential for the activity. Thus a number of 3,6-disubstituted-1,2,4-triazolo-[3,4- $b]$ 1,3,4-thiadiazole derivatives exhibited anticonvulsant activity in the MES screen. Some compounds like 82, 83, 84, $\mathbf{8 5 ,} 86$ and $\mathbf{8 7}$ showed more lipophilic character and were more active.

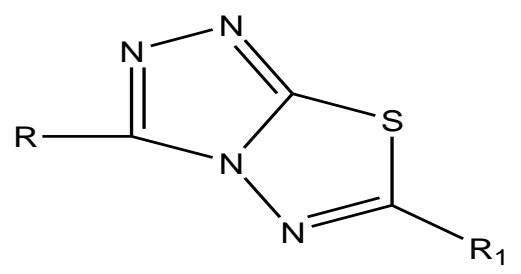

\begin{tabular}{|l|l|l|}
\hline Compounds & $\mathbf{R}$ & $\mathbf{R}_{\mathbf{1}}$ \\
\hline 82 & $\mathrm{C}_{6} \mathrm{H}_{5} \mathrm{CH}_{2^{-}}$ & $2-\mathrm{Br} \mathrm{C}_{6} \mathrm{H}_{4-}^{-}$ \\
\hline 83 & $\mathrm{C}_{6} \mathrm{H}_{5} \mathrm{CH}_{2-}$ & $\mathrm{C}_{10} \mathrm{H}_{7} \mathrm{CH}_{2}$ \\
\hline 84 & $\mathrm{C}_{6} \mathrm{H}_{5} \mathrm{OCH}_{2^{-}}$ & $4-\mathrm{Br} \mathrm{C}_{6} \mathrm{H}_{4}-$ \\
\hline 85 & $\mathrm{C}_{6} \mathrm{H}_{5} \mathrm{OCH}_{2^{-}}$ & $\mathrm{C}_{8} \mathrm{H}_{6} \mathrm{NCH}_{2^{-}}$ \\
\hline 86 & $2-\mathrm{OHC}_{6} \mathrm{H}_{4^{-}}$ & $3-\mathrm{BrC}_{6} \mathrm{H}_{4}$ \\
\hline 87 & $2-\mathrm{OHC}_{6} \mathrm{H}_{4}^{-}$ & $\mathrm{C}_{10} \mathrm{H}_{7} \mathrm{CH}_{2^{-}}$ \\
\hline
\end{tabular}

Fig28. Structure formulae of 3,6-disubstituted-1,2,4-triazolo-1,3,4-thiadiazole derivatives

Mohammad Shahar Yar et al. (2009)[34] synthesized a series of five membered heterocyclics and evaluated for their anticonvulsant activity by determining their ability to provide protection against convulsions induced by electroconvulsometer. Among the synthesized compounds, (88) 2-(4-chlorophenyl)amino-5-(4-pyridyl)-1,3,4thiadiazole was found promising compounds of the series after administration of $25 \mathrm{mg} / \mathrm{kg}$ of test compounds.<smiles>Clc1ccc(Nc2nnc(-c3ccncc3)s2)cc1</smiles> 
Figure 29. Structure formulae of 2-(4-chlorophenyl)amino-5-(4-pyridyl)-1,3,4-thiadiazole Nadeem Siddiqui et al.(2009)[35] synthesized a series of 2,5-disubstituted-1,3,4-thiadiazole derivatives and evaluated for their anticonvulsant activity in MES test. Whenever, Rotorod method was used to determine the neurotoxicity. Among them compounds (89), (90), and (91) produced significant protective effect on MES induced seizure. Whereas other remains compounds showed moderate protective effect. All the compounds were evaluated for their neurotoxicity using rotorod method given in the dose of $100 \mathrm{mg} / \mathrm{kg}$. None of the compounds showed neurotoxicity.

The SAR study of synthesized compounds reveals that different electron donating or electron withdrawing groups attached to phenyl ring as substituent linked to sulfonyl group are studied for anticonvulsant efficacy. It has been investigated that compounds bearing the groups like nitro, phenoxy and halogens on phenyl ring possess high potency in MES. The result of these compounds concluded that the introduction of a piperazine group at position 5 of thiadiazole ring and 3,5-bis(trifluoromethyl) positions of the benzenesulfonyl moiety (compound (89)) showed the best anticonvulsant activity. Whereas, compounds (90) and (91) possessing trifluoromethyl substituent at different positions of the benzenesulfonyl moiety showed good anticonvulsant activity in the MES model. Both compounds did not exhibit neurotoxicity at the highest administered dose. Further introduction of nitro group and halogen groups showed moderate anticonvulsant activity. The presence of cyano group at aryl ring has moderate activity. Although naphthalene group, dimethyl, and tert_butyl, were moderately active in the MES test; compounds with phenyl ring exhibited considerable anticonvulsant activity in comparison to methyl group.

These observation suggested that compound having electron withdrawing groups, produced excellent anticonvulsant activity. It has been established that there are at least three parameters for anticonvulsant drugs, that is (i) lipophilic domain (L), (ii) hydrophobic unit (R), and (iii) electron donar (D) system. Thus the proposed pharmacophore model for (89) includes all the above factors important for bioactivity. Therefore, the nature of groups in sulfonyl moiety is very important for anticonvulsant activity in MES model.
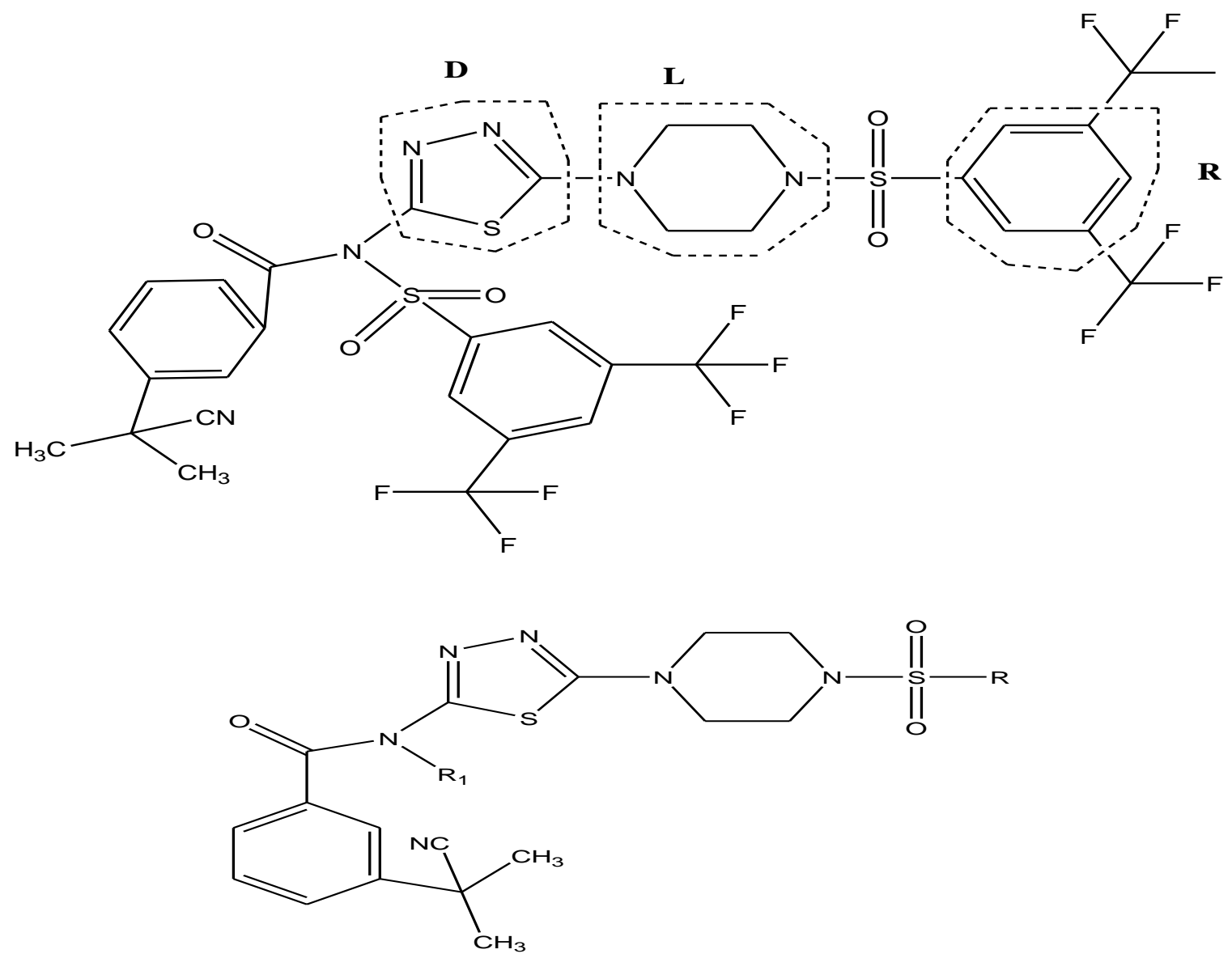
American Research Journal of Pharmacy, Volume 1, Issue 1, 2015

ISSN 2380-5706

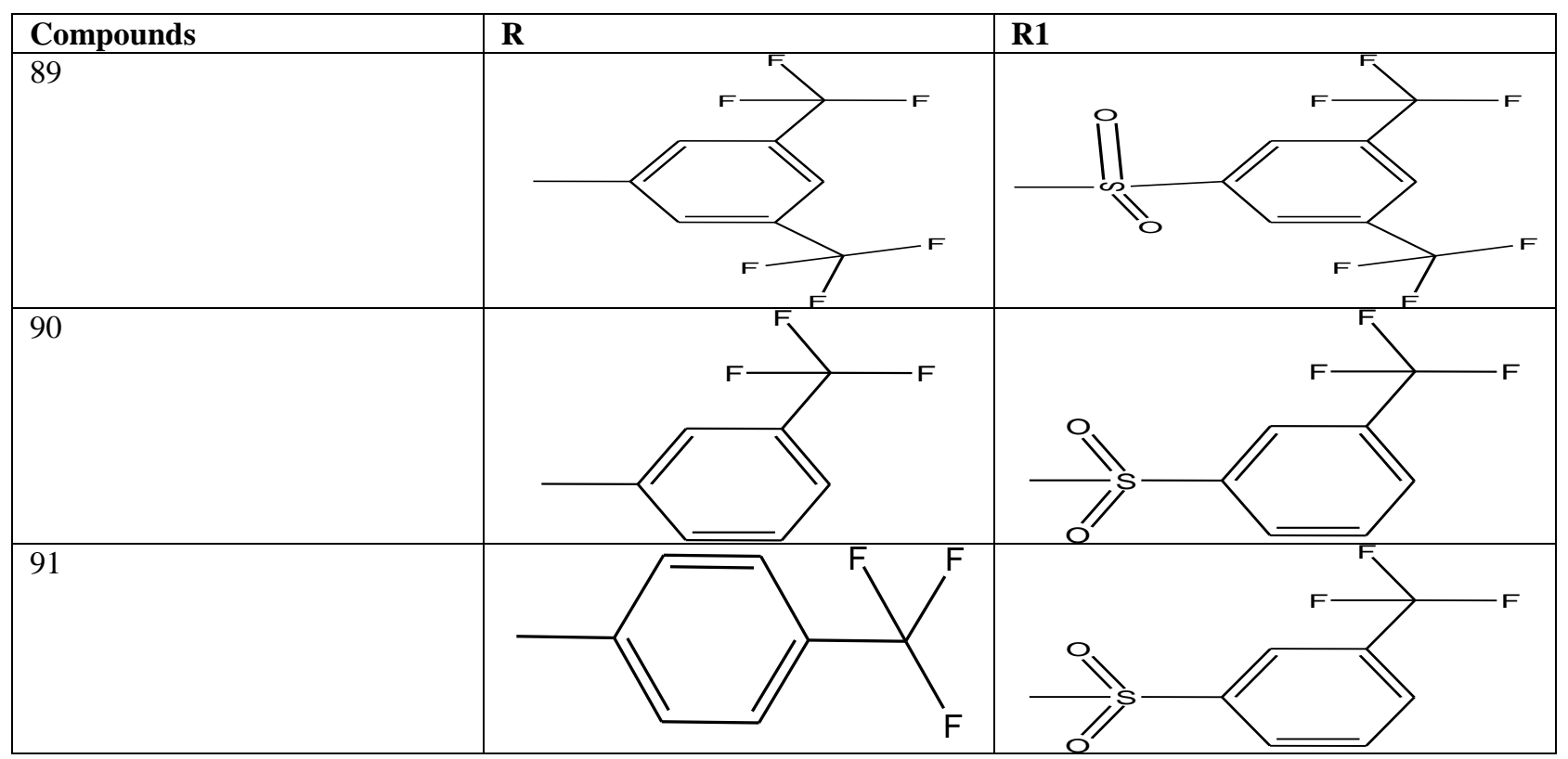

Fig30. Structure formulae of 2,5-disubstituted-1,3,4-thiadiazole derivatives

Priyabrata Pattanayak et al.(2009)[36] synthesized a series of thiadiazole derivatives and evaluated them for the anticonvulsant activity. Among the synthesized compounds 92, 93 and 94 were found to possess significant anticonvulsant activity in both models.

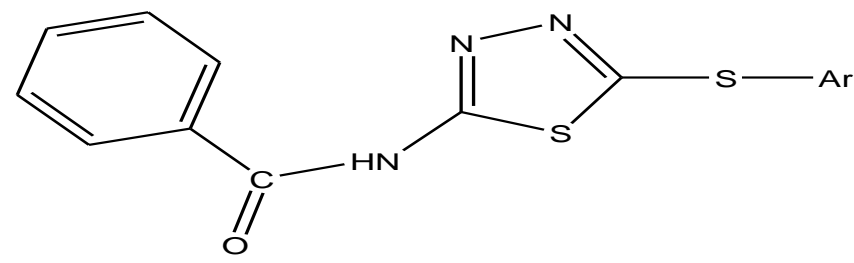

\begin{tabular}{|l|l|}
\hline Compounds & $\mathbf{A r}$ \\
\hline 92 & $4-\mathrm{C} 6 \mathrm{H} 4 \mathrm{SO} 2 \mathrm{Cl}$ \\
\hline 93 & $4-\mathrm{C} 6 \mathrm{H} 4 \mathrm{SO} 2 \mathrm{NH} 2$ \\
\hline 94 & $4-\mathrm{C} 6 \mathrm{H} 4 \mathrm{~F}$ \\
\hline
\end{tabular}

Fig31. Structure formulae of 2-amino-5-sulfanyl-1,3,4-thiadiazoles

Hemlata Kaur et al. (2010) [37] synthesized a novel series of substituted oxa/thiadiazolylazetidinonyl/ thiazolidinonylcarbazoles derivatives and screened for anticonvulsant activities. In the synthesized series compound 99 showed promising anticonvulsant activity. Thiadiazole ring containing compounds was showed better biological activities than compounds having oxadiazole ring. In these compounds, 100 showed potent (80\%) anticonvulsant activity as well as compounds $\mathbf{9 5 - 9 9}$ showed good anticonvulsant response when compared to the other compounds and the reference drugs.

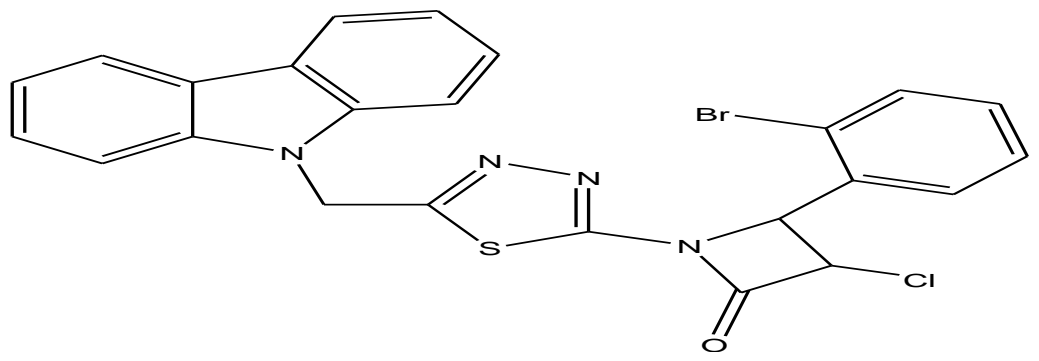




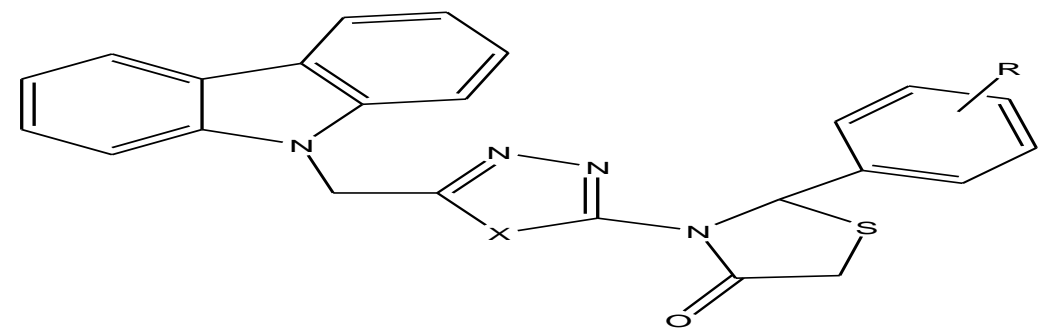

\begin{tabular}{|l|l|l|}
\hline Compounds & $\mathbf{R}$ & $\mathbf{X}$ \\
\hline $\mathbf{9 5}$ & $4-\mathrm{OH}$ & $\mathrm{S}$ \\
\hline $\mathbf{9 6}$ & $2,4-\mathrm{OH}$ & $\mathrm{S}$ \\
\hline $\mathbf{9 7}$ & $4-\mathrm{OH}, 3-\mathrm{OCH}_{3}$ & S \\
\hline $\mathbf{9 8}$ & $4-\mathrm{N}\left(\mathrm{CH}_{3}\right)_{2}$ & S \\
\hline $\mathbf{9 9}$ & $2-\mathrm{Br}$ & S \\
\hline
\end{tabular}

Fig32. Structure formulae of substituted oxa/thiadiazolylazetidinonyl/thiazolidinonylcarbazoles

Harish Rajak et al.(2010) [38] synthesized a novel series of N1-\{5-[(1H-indol-3-ylmethyl)-1,3,4-thiadiazol-2-yl $\}-$ N4-(4-substituted benzaldehyde)-semicarbazones, N1-\{5-[(1H-indol-3-yl methyl)-1,3,4-thiadiazol-2-yl $\}-\mathrm{N} 4-[1-(4-$ substituted phenyl)ethanone]-semicarbazones and N1-\{5-[(1H-indol-3-ylmethyl)-1,3,4-thiadiazol-2-yl $\}-\mathrm{N} 4-[1-(4-$ substituted phenyl) (phenyl) methanone]-semicarbazones and evaluated for their anticonvulsant potential using maximal electroshock seizure (MES) and subcutaneous pentylenetrtrazole ( scPTZ) models. The minimal motor impairment (neurotoxicity) evaluated by rotorod test. Among them, compound N1-\{5-[(1H-indol- 3-ylmethyl)1,3,4-thiadiazol-2-yl\}-N4-[1-(4-hydroxyphenyl)(phenyl) methanone]-semicarbazone 101 showed the most active compound in maximal electroshock seizure (at $100 \mathrm{mg} / \mathrm{kg}$ after $0.5 \mathrm{~h}$ and at $300 \mathrm{mg} / \mathrm{kg}$ after $4.0 \mathrm{~h}$ ) and subcutaneous pentylenetetrazole model (at $300 \mathrm{mg} / \mathrm{kg}$ after $4.0 \mathrm{~h}$ ) without any neurotoxicity (up to $300 \mathrm{mg} / \mathrm{kg}$ after $4.0 \mathrm{~h}$ ).

The SAR study of synthesized compounds reveals that the introduction of hydroxy and nitro group on distant phenyl ring showed high potency in MES and $s c$ PTZ tests, whereas replacement of these groups with methoxy and chloro groups on the distant phenyl ring has resulted in compounds with a decrease in anticonvulsant activity. These results concluded that anticonvulsant activity of test compounds changes on varying $p$-substituted group on aryl moiety as follows: hydroxy $>$ nitro $>$ methoxy $>$ chloro $>$ methyl group.

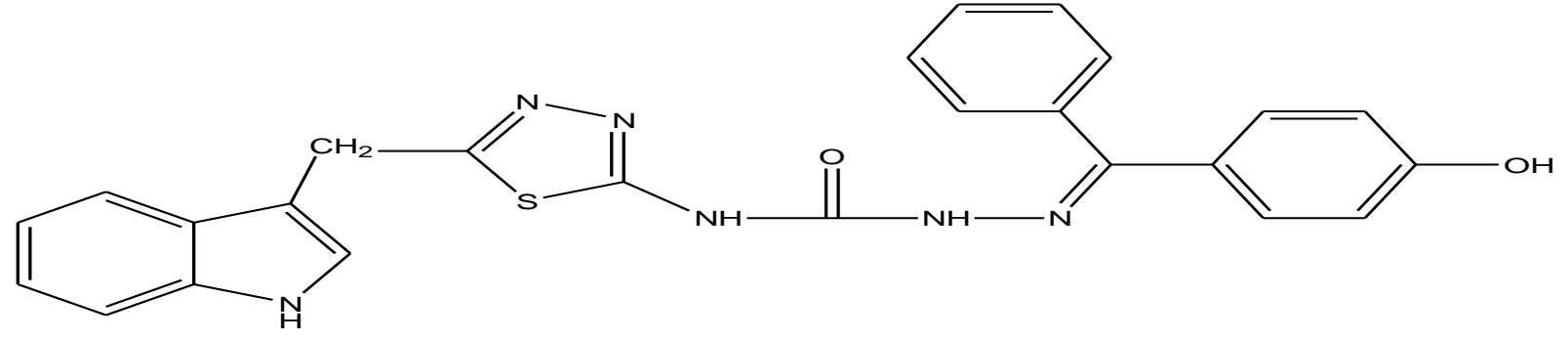

101

Fig33. Structure formulae of 2,5-disubstituted 1,3,4-thiadiazoles

Rajesh Sharma et al. (2011)[39] synthesized a new series of 2-amino-5-sulfanyl-1,3,4-thiadiazole and screened for anticonvulsant activity. Among them compounds 102, 103, 104, 105 and 106 exhibited significant anticonvulsant activity.

The SAR study of synthesized compounds reveals that substitution of sulphonamide group on $\mathrm{R}$ position and chloride group on R1 position in compound 102, appreciable anxiolytic and anticonvulsant activity but little effect on antidepressant activity. Whereas compound $\mathbf{1 0 3}$ having sulphonamide group on R position and fluoride group on R1 position produced significant effects on CNS (antidepressant, anxiolytic and anticonvulsant). Compound 104 having sulphonyl chloride group on $\mathrm{R}$ position and trifluoro methyl group on R1 position exerted maximum activity among all compounds. Among the halogen (electron-withdrawing group) substituted compounds only compound having fluoride or trifluoromethyl group and up to some extent chloride group (compound 102 showed anxiolytic 
and anticonvulsant activity) on R1 position possessed significant central nervous system activity, the possible reason could be a fluorine atomare small in size, lipophilic in nature and ability to form strong hydrogen bond. Further compound 105 having methyl (electron donating) group on R1 position produced broad range of central nervous system activity (antidepressant, anxiolytic and anticonvulsant).

But in the compound 106 having sulphonyl chloride group on R1 position and sulphonamide group on R position also produced significant CNS (antidepressant, anxiolytic and anticonvulsant).

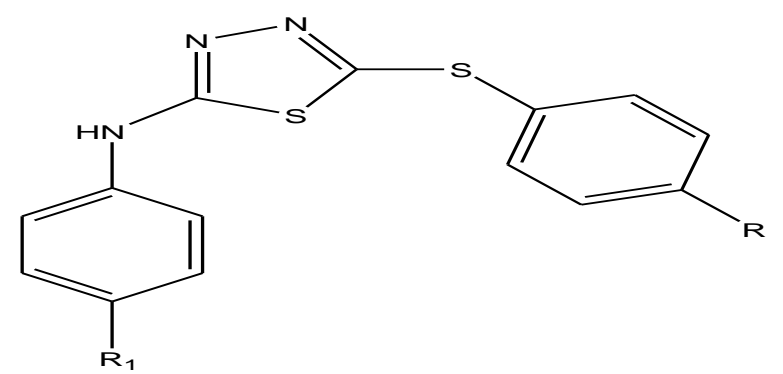

\begin{tabular}{|l|l|l|}
\hline Compounds & $\mathbf{R}$ & $\mathbf{R}_{\mathbf{1}}$ \\
\hline 102 & $-\mathrm{SO}_{2} \mathrm{NH}_{2}$ & $-\mathrm{Cl}$ \\
\hline 103 & $-\mathrm{SO}_{2} \mathrm{NH}_{2}$ & $-\mathrm{F}$ \\
\hline 104 & $-\mathrm{SO}_{2} \mathrm{NH}_{2}$ & $\mathrm{CH}$ \\
\hline 105 & $-\mathrm{SO}_{2} \mathrm{Cl}$ & $-\mathrm{CF}_{3}$ \\
\hline 106 & $-\mathrm{SO}_{2} \mathrm{NH}_{2}$ & $-\mathrm{SO}_{2} \mathrm{Cl}$ \\
\hline
\end{tabular}

Fig34. Structure formulae of 2-amino-5-sulfanyl-1,3, 4-thiadiazole derivatives

Nadeem Siddiqui et al.(2011) [40] synthesized a series of thiazole-substituted thiadiazole derivatives using and evaluated them for anticonvulsant activity by using maximal electroshock seizure (MES) and subcutaneous pentylenetetrazole (scPTZ) models. Among them three compounds 107, 108 and 109 were showed the potent anticonvulsant activity in both the models at the lowest dose $30 \mathrm{mg} / \mathrm{kg}$ after $0.5 \mathrm{~h}$ with comparable ED50 and better TD50 values than some standard drugs. These compounds showed protective indices of 25.8, 11.3, and 43.6 respectively. These compounds were not showed the neurotoxicity but exert lesser toxic effects on liver. Compound 107 and 109 possessed good anti-MES activity with ED50 of 19.1 and $12.6 \mathrm{mg} / \mathrm{kg}$, respectively. The much higher TD50 values exhibited by the compounds $\mathbf{1 0 7}$ as well as in the scPTZ screen compound 107 displayed better ED50 values than most of the standard drugs with higher PI.

SAR study reveal that the phenyl ring attached to the thiazole moiety was substituted with electron withdrawing groups $(\mathrm{NO} 2 \mathrm{Br} \backslash \mathrm{Cl})$ effect the activity and the phenyl ring attached to the thiadiazole moiety was substituted with different electron releasing groups at different positions does not have marked effect on the activity. The bromosubstituted derivatives were comparatively more neurotoxic than the other derivatives of the series.

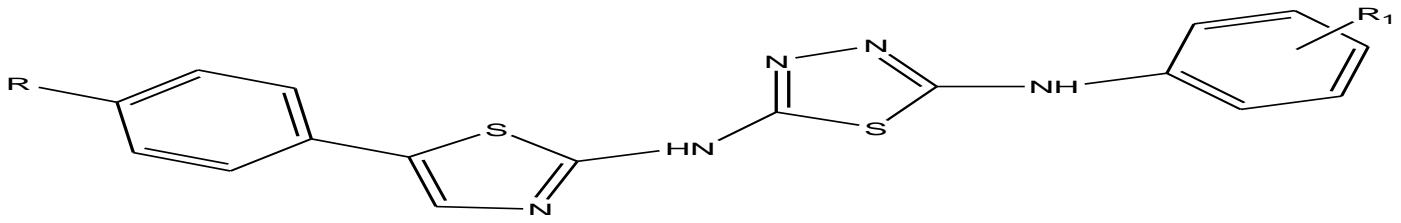

\begin{tabular}{|l|l|l|}
\hline Compounds & $\mathbf{R}$ & $\mathbf{R}_{\mathbf{1}}$ \\
\hline 107 & $\mathrm{Br}$ & $4-\mathrm{OCH} 3$ \\
\hline 108 & $\mathrm{NO} 2$ & $4-\mathrm{CH} 3$ \\
\hline 109 & $\mathrm{NO} 2$ & $4-\mathrm{OCH} 3$ \\
\hline
\end{tabular}

Fig35. Structure formulae of thiazole-substituted thiadiazole derivatives

Harish Rajak et al. (2012) [41] synthesized a series of novel semicarbazones containing 1,3,4-Thiadiazole and Quinazoline ring and evaluated them for anticonvulsant activity. Among them compounds i.e., 110 and 113-121 produced anticonvulsant activity in the MES screening as compared to $57 \%$ of the compounds i.e., 111, 112-114, 116, 117, 119 and 120 in the $s c$ PTZ test. Thus, the compounds exhibited some MES selectivity indicating their effectiveness in generalized seizures of the tonic-clonic (grandmal) type. The most potent N1-\{5-\{[(2-methyl-4- 
oxoquinazolin-3(4H)-yl)

amino]methyl\}-1,3,4-thiadiazol-2-yl\}-N4-[1-(4-nitrophenyl)

(phenyl) methanone]semicarbazone 120 investigated, in maximal electroshock seizure (at $100 \mathrm{mg} / \mathrm{kg}$ after $0.5 \mathrm{~h}$ and at 300 $\mathrm{mg} / \mathrm{kg}$ after $4.0 \mathrm{~h}$ ) and subcutaneous pentylenetetrazole model (at $300 \mathrm{mg} / \mathrm{kg}$ after $4.0 \mathrm{~h}$ ) without any neurotoxicity (up to $300 \mathrm{mg} / \mathrm{kg}$ after $4.0 \mathrm{~h}$ ).

SAR study of synthesized compounds reveals that the introduction of nitro or chloro on distant phenyl ring possesses high potency in MES and $s c$ PTZ tests. However, replacement of these substituent with methyl or methoxy groups on the distant phenyl ring show with a decrease in anticonvulsant activity. The result concluded that the antiepileptic activity of test compounds changes on varying $p$-substituted group on aryl moiety as follows: nitro > chloro > hydroxy > methoxy > methyl group.

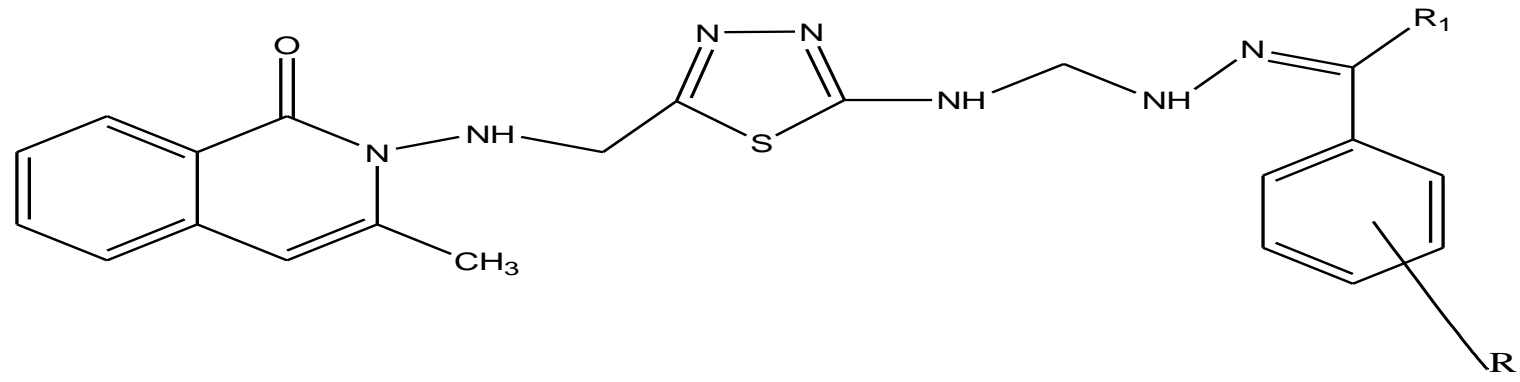

\begin{tabular}{|l|l|l|l|l|}
\hline Compounds & R & R1 & MES Activity & ScPTZ Activity \\
\hline 110 & $\mathrm{H}$ & $4-\mathrm{NO}_{2}$ & MES & - \\
\hline 111 & $\mathrm{H}$ & $4-\mathrm{OH}$ & - & ScPTZ \\
\hline 112 & $\mathrm{H}$ & $4-\mathrm{OCH}_{3}$ & - & ScPTZ \\
\hline 113 & $\mathrm{H}$ & $4-\mathrm{Cl}$ & MES & ScPTZ \\
\hline 114 & $\mathrm{CH}_{3}$ & $4-\mathrm{OH}$ & MES & ScPTZ \\
\hline 115 & $\mathrm{CH}_{3}$ & $4-\mathrm{OCH}_{3}$ & MES & - \\
\hline 116 & $\mathrm{CH}_{3}$ & $4-\mathrm{NO}_{2}$ & MES & ScPTZ \\
\hline 117 & $\mathrm{CH}_{3}$ & $4-\mathrm{Cl}$ & MES & ScPTZ \\
\hline 118 & $\mathrm{C}_{6} \mathrm{H}_{5}$ & $\mathrm{H}$ & MES & - \\
\hline 119 & $\mathrm{C}_{6} \mathrm{H}_{5}$ & $4-\mathrm{OH}_{3}$ & MES & ScPTZ \\
\hline 120 & $\mathrm{C}_{6} \mathrm{H}_{5}$ & $4-\mathrm{NO}_{2}$ & MES & ScPTZ \\
\hline 121 & $\mathrm{C}_{6} \mathrm{H}_{5}$ & $4-\mathrm{OCH}_{3}$ & MES & - \\
\hline
\end{tabular}

Fig36. Structure formulae of semicarbazones containing 1,3,4-Thiadiazole and Quinazoline ring

Hemlata Kaur et al. (2012) [42] synthesized two series of 2-((2-((5-benzylideneamino)-1,3,4-oxa/thiadiazol-2yl)methyl)hydrazinyl) methyl)-benzo[b][1,4]oxa/thiazepin-4(5H)-ones, 2-((2-((5-(4-oxo-2-substitutedphenyl thiazolidin- 3-yl)-1,3,4-oxa/thiadiazol-2 yl)methyl) hydrazinyl) methyl)benzo [b] [1,4]oxa/thiazepin-4(5H)-ones and 2-((2-((5-(3-chloro-2-(substitutedphenyl)-4-oxoazetidin-1-yl)-1,3,4-oxa/thia diazol-2 yl)methyl) hydrazinyl) methyl) benzo[b][1,4] oxa/thiazepin-4(5H)-ones and evaluated them for the anticonvulsant activity. Among them compound 122 showed the most compound (having 2-bromophenyl ring at $2^{\text {nd }}$ position of thiazolidinone ring) having $90 \%$ anticonvulsant activity.

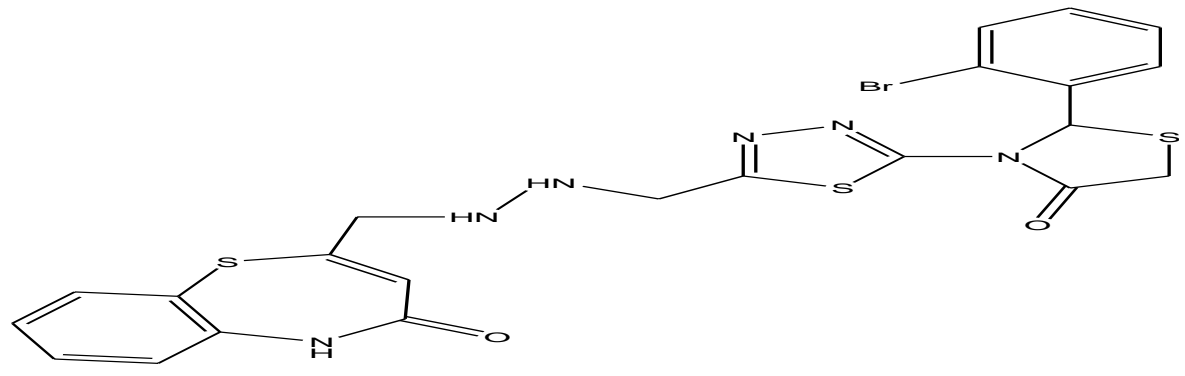

122

Fig37. Structure formulae of substituted benzoxazepine and benzothiazepine 
Kikkeri P et al.(2013) [43]synthesized a new pyrazine substituted 1,3,4-thiadiazole derivatives and evaluated for their anticonvulsant activity against maximal electroshock (MES) seizure method at the dose of $100 \mathrm{mg} / \mathrm{kg}$. Neurotoxicity was performed by Rotarod method and the compounds $\mathbf{1 2 3}$ and $\mathbf{1 2 4}$ produced highly significant protective effect similar to that of standard (phenytoin).

The SAR study of these compounds indicate that the introduction of a piperazine group of pyrazine ring and 3, 5bis(trifluoromethyl) positions of the benzenesulfonyl moiety showed the best anticonvulsant activity in 123. Another approach of substitution in compound $\mathbf{1 2 4}$ contains halogen and thiophene group showed good anticonvulsant activity in the MES model. Both compounds did not exhibit neurotoxicity at the highest administered dose. The results concluded that the introduction of phenyl ring exhibited more anticonvulsant activity in comparison to methyl group.

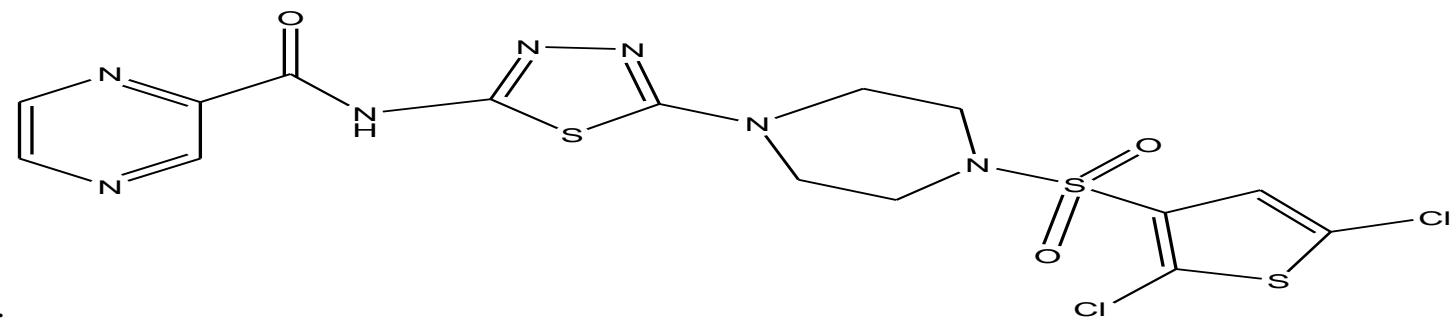

123

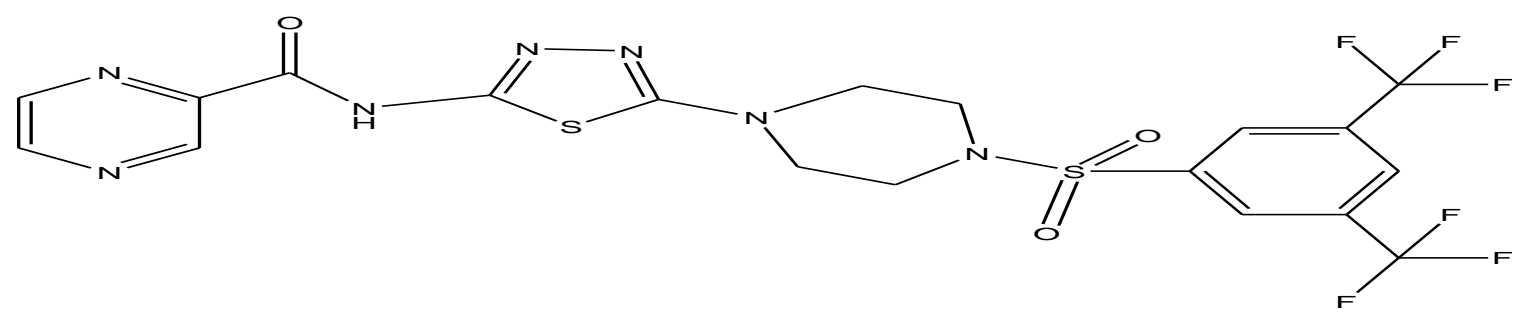

124

Fig38. Structure formulae of pyrazine substituted 1,3,4-thiadiazole derivatives

Kikkeri N. Mohana et al. (2013) [44] synthesized a new series of indazole substituted-1,3,4-thiadiazole derivatives and evaluated them for the anticonvulsant activity against maximal electroshock (MES) seizure model in male Wistar rats. Among them, compounds $\mathbf{1 2 5}$ and $\mathbf{1 2 6}$ showed the most potent of this series and no neurotoxicity was fund at the maximum dose administered $(100 \mathrm{mg} / \mathrm{kg})$.

The SAR study of synthesized compounds reveals that the nature of groups in sulfonyl moiety is very important for anticonvulsant. Different electron donating or electron withdrawing groups attached to phenyl ring as substituent linked to sulfonyl group are investigated for anticonvulsant efficacy. The result concluded compounds bearing the groups like nitro and halogens on phenyl ring possess high potency in MES. The structural activity relationship study of these compounds indicate that the introduction of a piperazine group of thiadiazole ring and 3,5bis(trifluoromethyl) positions of the benzenesulfonyl moiety exerted best anticonvulsant activity in $\mathbf{1 2 5}$. Compound 126 contains halogen and thiophene group produced good anticonvulsant activity in the MES model activity in MES model.

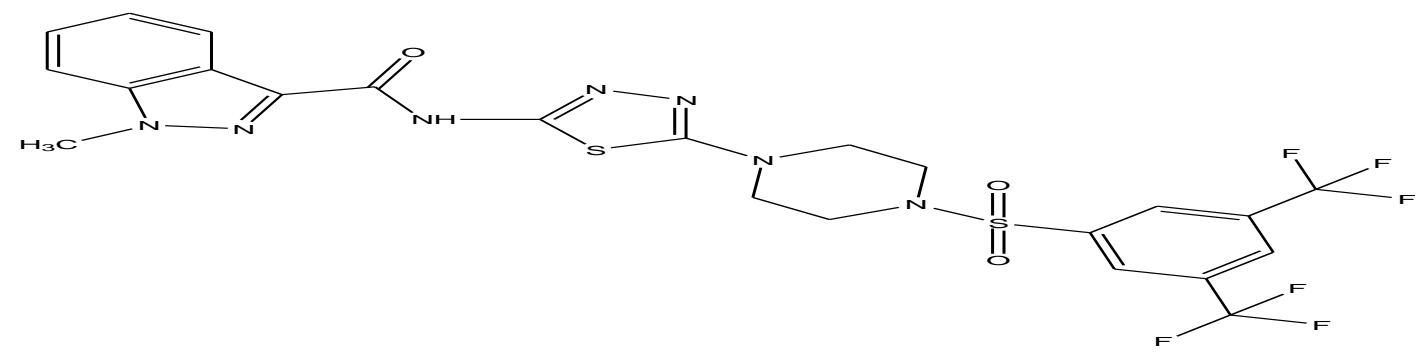




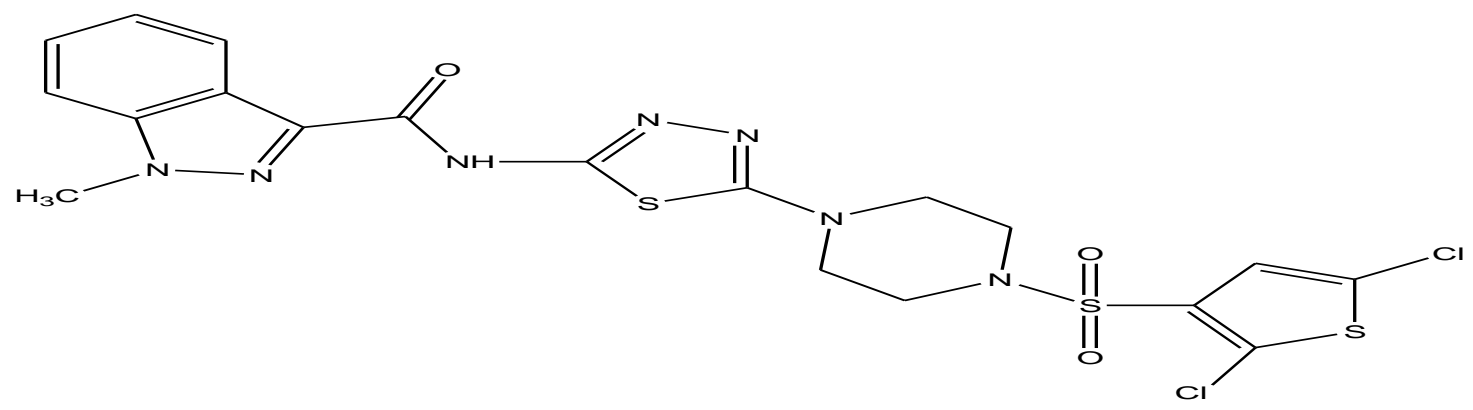

126

Figure 39. Structure formulae of indazole substituted-1,3,4-thiadiazole derivatives

S. Botros et al. (2013) [45] synthesized Hybrids between phenytoin and thiosemicarbazide, 1,3,4-thiadiazole and evaluated them for anticonvulsant activity by using standard maximal electroshock (MES) and subcutaneous pentylenetetrazole (scPTZ) screens in mice. The neurotoxicity was determined applying the rotarod test. All test compounds (127-131) showed varying degree (20-60\%) of anticonvulsant activity in the scPTZ and MES model.

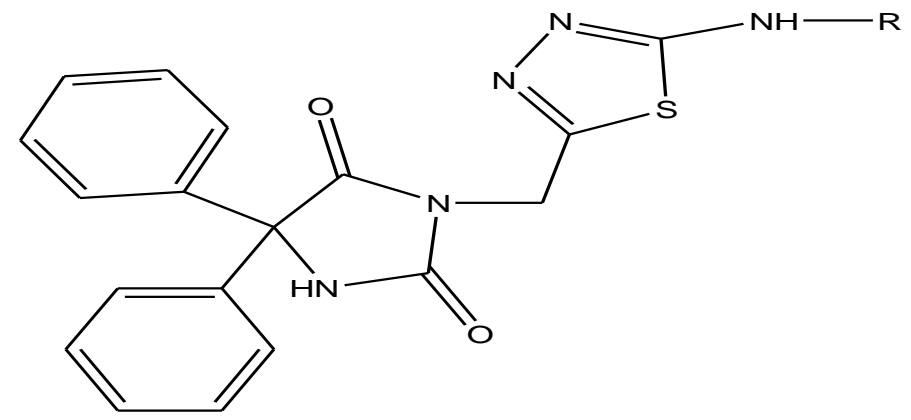

\begin{tabular}{|l|l|}
\hline Compounds & $\mathbf{R}$ \\
\hline 127 & $\mathrm{C}_{2} \mathrm{H}_{5}$ \\
\hline 128 & $\mathrm{C}_{6} \mathrm{H}_{5}$ \\
\hline 129 & $4-\mathrm{CH}_{3} \mathrm{C}_{6} \mathrm{H}_{4}$ \\
\hline 130 & $4-\mathrm{OCH}_{3} \mathrm{C}_{6} \mathrm{H}_{4}$ \\
\hline 131 & $4-\mathrm{ClC}_{6} \mathrm{H}_{4}$ \\
\hline
\end{tabular}

Fig40. Structure formulae of new phenytoin derivatives

Mohammad Yusuf et al.(2013) [46] synthesized a novel imines derived and evaluated for anticonvulsant activity. Among them 5-amino-1,3,4-thiadiazole-2-thiol exhibited shows potential anticonvulsant activity. The compounds 5\{1-(4-Chlorophenyl)-3-[4-(methoxy-phenyl)-prop-2-en-1-ylidene]amino\}-1,3,4-thiadiazole-2-thiol (139), 5-\{[1-(4chloro-phenyl)]-3-[4-(dimethyl-amino-phenyl)- prop-2-en-1-ylidene]amino \}-1,3,4-thiadiazole-2-thiol (140) and 5\{[1-(4-chloro-phenyl)]-3-[(4-amino-phenyl)-prop-2-en-1-ylidene]amino $\}$-1,3,4-thiadiazole-2-thiol(143)showed 100\% activity in comparison with standard Acetazolamide drug. Neither compound 140 nor 143 had shown the neurological toxicity in Rotarod and Ethanol Potentiation tests.

SAR study of the synthesized compounds indicated that thiadiazole ring, free thiol and imine group are part of the main pharmacophore responsible for exhibiting the anticonvulsant activity.

Thiadiazole ring have two nitrogens at 1, 2 position which formed mesoionic complex with the hydrogen of the hydroxyl group of amino acids threonine (Thr), positioned as Thr-200 and Thr-199 in the polypeptide chain of the hCA-II enzyme. Further investigation of compounds in 132-137 possessed chloro, fluoro and nitro electron withdrawing groups at positions 2 and 4 of the benzyl ring and exhibited average levels of bioactivity. However, compounds 133 and 137 were active at 50\% and above in anticonvulsant tests.

Whereas, the compounds in (138-144) shown potent anticonvulsant activity as per sequences - $\mathrm{N}(\mathrm{CH} 3) 2$, - $\mathrm{NH} 2$ and $\mathrm{OH}$ substitutions, although the introduction by $\mathrm{H}, \mathrm{OCH} 3$ and $\mathrm{Cl}$ groups reduced the activity. The $\mathrm{R}_{1}$ substitution at 
para-position was preferred in comparison with substitution at position 3 (meta) of the $\mathrm{C}_{6}$ aromatic ring which did not showed enough potency levels. The results concluded that the presence of electron rich and comparatively bulky group with availability of free electrons, such as $\mathrm{OCH} 3,-\mathrm{N}(\mathrm{CH} 3) 2$ and $-\mathrm{NH} 2$ in comparison with $\mathrm{OH}, \mathrm{CH} 3$ and $\mathrm{Cl}$ atom at position 4 of the benzene ring away from thiadiazole moiety as preferred substitutions for producing higher biological activity for (138-144) compound. Whenever, the 132-137compounds having electron-withdrawing group at $\mathrm{R}$ position of the benzene ring showed good anti-convulsant activity but in the compounds (138-144), the electron-donating groups at R1 position and electron-withdrawing groups at R2 position showed potent anticonvulsant activity.

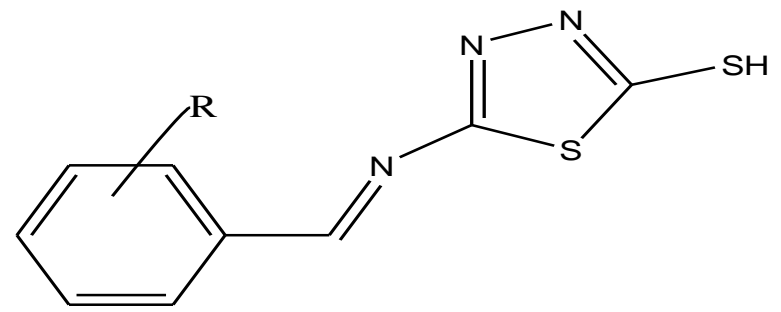

\begin{tabular}{|l|l|}
\hline Compounds & $\mathbf{R}$ \\
\hline 132 & $2-\mathrm{Cl}$ \\
\hline 133 & $4-\mathrm{Cl}$ \\
\hline 134 & $2-\mathrm{NO}_{2}$ \\
\hline 135 & $4-\mathrm{NO}_{2}$ \\
\hline 136 & $2-\mathrm{F}$ \\
\hline 137 & $4-\mathrm{F}$ \\
\hline
\end{tabular}

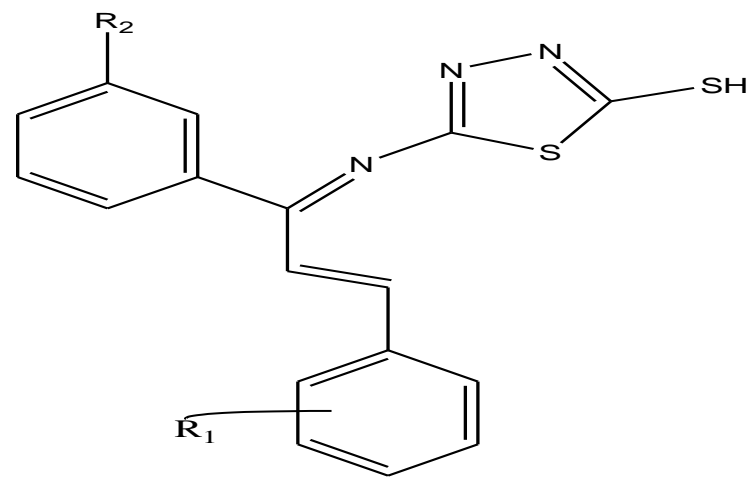

\begin{tabular}{|l|l|l|}
\hline Compounds & $\mathbf{R}_{\mathbf{1}}$ & $\mathbf{R}_{\mathbf{2}}$ \\
\hline 138 & $\mathrm{H}$ & $\mathrm{H}$ \\
\hline 139 & $4-\mathrm{OCH}_{3}$ & $\mathrm{Cl}$ \\
\hline 140 & $4-\mathrm{N}_{3} \mathrm{CH}_{3}$ & $\mathrm{Cl}$ \\
\hline 141 & $4-\mathrm{Cl}$ & $\mathrm{Cl}$ \\
\hline 142 & $3-\mathrm{OH}$ & $\mathrm{Cl}$ \\
\hline 143 & $4-\mathrm{NH}_{2}$ & $\mathrm{Cl}$ \\
\hline 144 & $4-\mathrm{CH}_{3}$ & $\mathrm{Cl}$ \\
\hline
\end{tabular}

Fig41. Structure formulae of 5-Amino-1,3,4-Thiadiazole-2-Thiol Conjugated Imine Derivatives

Rajesh Sharma et al. (2014) [47] synthesized a series of 2-(2-(3-(4-chlorophenyl)-6-oxo-5,6- dihydropyridazin1(4H)yl)acetyl)hydrazine carbothioamide and 2-((5-amino-1,3,4-thiadiazol-2-yl)methyl)-6-(4- chlorophenyl)-4,5dihydropyridazin $-3(2 \mathrm{H})$-one derivatives and evaluated them for anticonvulsant activity. Among them the compound $145(85.44 \%)$ showed promising anticonvulsant activity by protection against tonic hind limb extensor phase in maximal electroshock model (MES) at ( $50 \mathrm{mg} / \mathrm{kg}$ ) compared to standard drug phenytoin and also showed significant anticonvulsant activity by protection against pentylenetetrazole-induced generalized convulsions in pentylenetetrazole model (PTZ) at $(100 \mathrm{mg} / \mathrm{kg})$ compared to standard drug diazepam shown significant anticonvulsant activity against MES and PTZ induced seizure in albino mice after IP administration of 50 and 100 $\mathrm{mg} / \mathrm{kg}$ body weight dose, respectively. 


\section{ISSN 2380-5706}

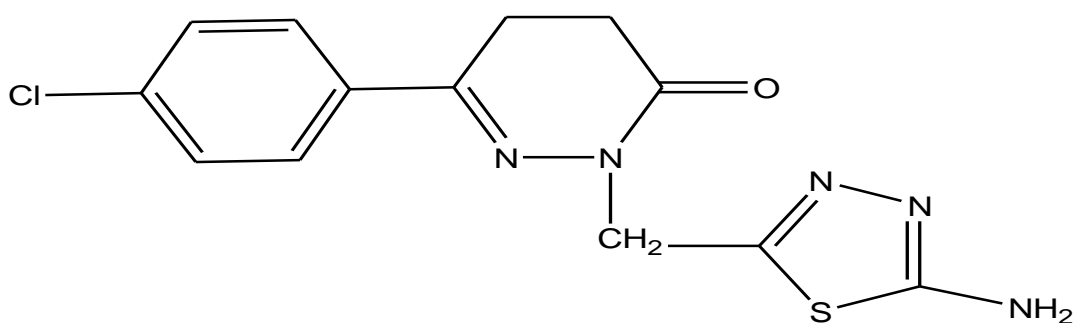

145

Fig42. Structure formulae of substituted 1,3,4-thiadiazoles

K. P. Harish et al.(2014) [48] synthesized a series of 2-amino-5-sulphanyl-1,3,4-thiadiazole derivatives and evaluated for the anticonvulsant activity. Among them, compounds 146, 147 and 148 exhibited excellent anticonvulsant activity in comparison to the reference drugs.

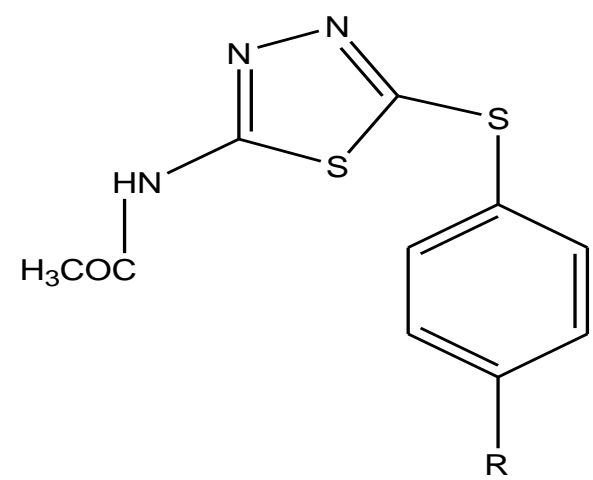

\begin{tabular}{|l|l|}
\hline Compounds & $\mathbf{R}$ \\
\hline 146 & $\mathrm{SO}_{2} \mathrm{NH}_{2}$ \\
\hline 147 & $\mathrm{CF}_{3}$ \\
\hline 148 & $\mathrm{~F}$ \\
\hline
\end{tabular}

Fig43. Structure formulae of 2-amino-5-sulphanyl-1,3,4-thiadiazole derivatives

\section{CONCLuSiON}

Thiadiazole is belong to the triheterocycle templet which composed of two electron-deficient carbon atoms these are interconnected with nitrogen atoms, and a sulfur atom with lone electron pairs. However, this compound has an electron-deficient nature and pretty high thermotic stability. Due to this properties, it can hardly react whenever the introduction on the $\mathrm{C}^{\prime}$ or $\mathrm{C}^{\prime}$ position of 1,3,4-thiadiazoles are highly reactive. Hence, the nitrogen atoms tend to nucleophilic attack, and the carbon atoms can suffer both nucleophilic substitutions and electrophilic attacks. The introduction of common leaving susitutention on the 1,3,4-thiadiazole possessed very higher reactivity.

1,3,4-thiadiazoles exhibit versatile pharmacological activity, specialy wide range of derivative shown the most potent antconvulsant effect against a varity of in vivo animal models. Structure activity relationship of 1,3,4thiadiazole derivatives indicated that 1,3,4,-thiadiazole ring essential for the anticonvulsant activity. Substitution of halogens group containing phenyl on the 1,3,4-thiadaizole derivatives possessed anticonvulsant activity against MES and PTZ models. These results reveal that 1,3,4-thiadiazole and substituted electriphilic containing phenyl linked with 1,3,4-thiadiazole are the essential pharmacophore for the anticonvulsant activity.

On the behalf of existing literature the mechanism of action of 1,3,4-thiadiazole may be demonstrated that means these derivatives increase GABAA phathway via release the chloride ions and further control and prevent the firing of neurons in the Brain.

For the development 1,3,4-thiadaizole derivative may be a potent anticonvulsant agent via introducing different kinds of substitution on the nitrogen atoms and ring sulfur atom as well as amino groups and mercapto groups attached to the ring carbon atoms. 1,3,4-thiadiazole is the essential heterocycle which will certainly contribute in medicinal chemistry to the development of new anticonvulsant drug. The continuing focus of chemist to developing 
the thiadiazole scaffold and used of essential pharmacophores to make low molecular weight medicine with high efficacy and low side effects on the epileptic patient.

\title{
IV. ACKNOWLEDGEMENTS
}

The authors would like to express their gratitude to Babasaheb Bhimrao Ambedkar University (A Central University) Lucknow for providing the software and research data facilities.

\author{
Abbreviation \\ CNS $=$ Central nervous system \\ $\mathrm{CA}=$ Carbonic anhydrase \\ $\mathrm{SRB}=$ Sulforhodamine $\mathrm{B}$ \\ $A A Z=$ Acetazolamide \\ $M Z A=$ Methazolamide \\ SAR $=$ Structure-activity relationship \\ 3D-QSA =Three dimensional quantitative structure-activity relationships \\ $\mathrm{GABA}=\gamma$-Aminobutyric acid \\ NMDA $=$ N-Methyl-D-aspartic acid \\ ED 50 = effective dose for 50 percent \\ MES = maximal electroshock seizure \\ PTZ = Pentylenetetrazol
}

\section{REFERENCES}

[1] Shankar P Saha, Sushanta Bhattachrya, Biman Kanti Roy, Arindam Basu, Trishit Roy, Bibekananda Maity, Shyamal K Das. A prospective incidence study of epilepsy in a rural community of West-Bengal, India. Neurology Asia $2008 ; 13: 41$ -48 .

[2] John Greenfield Jr. Molecular mechanisms of antiseizure drug activity at GABAA receptors. Seizure 22 (2013) 589-600.

[3] Abhishek Kumar Jain, Simant Sharma, Ankur Vaidya, Veerasamy Ravichandran and Ram Kishore Agrawal. 1,3,4Thiadiazole and its Derivatives: A Review on Recent Progress in Biological Activities. Chem Biol Drug Des 2013; 81: 557-576.

[4] Supuran C.T., Scozzafava A. (2001) Carbonic anhydrase inhibitors. Curr Med Chem Immunol Endocrinol Metab Agents;1:61-97.

[5] Iizawa Y., Okonogi K., Hayashi R., Iwahi T., Yamazak T., Imada A. (1993) Therapeutic effect of cefozopran (SCE-2787), a new parenteral cephalosporin, against experimental infections in mice. Antimicrob Agents Chemother;37:100-105. Demirbas, D. Sahin, N. Demirbas, and S. A. Karaoglu, "Synthesis of some new 1,3,4-thiadiazol-2-ylmethyl-1,2,4-triazole derivatives and investigation of their antimicrobial activities," European Journal of Medicinal Chemistry, vol. 44, no. 7, pp. 2896-2903, 2009

[6] E. E. Oruc, S. Rollas, F. Kandermirli, N. Shvets, and A. S. Dimoglo, "1,3,4-thiadiazole derivatives. Synthesis, structure elucidation, and structure-antituberculosis activity relationship investigation," Journal of Medicinal Chemistry, vol. 47, pp.6760-6676, 2004.

[7] Foroumadi, A.; Kiani, Z.; Soltani, F. Farmaco 2003, 58, 1073.

[8] M. D. Kamal, H. A. Gawad, E. A. Rageb, M. Ellithey, and H. A. Mohamed, "Synthesis, anticonvulsant, and antiinflammatory evaluation of some new benzotriazole and benzofuran-based heterocycles," Bioorganic and Medicinal Chemistry, vol. 14, no. 11, pp. 3672-3680, 2006

[9] P. Mullick, S. A. Khan, S. Verma, and O. Alam, "Thiadiazole derivatives as potential anticonvulsant agents," Bulletin of the Korean Chemical Society, vol. 32, no. 3, pp. 1011-1016, 2011.

[10] Clerici, F.; Pocar, D.; Guido, M.; Loche, A.; Perlini, V.; Brufani, M. J. Med. Chem. 2001, 44, 931.

[11] Hasui, T.; Matsunaga, N.; Ora, T.; Ohyabu, N.; Nishigaki, N.; Imura, Y.; Igata, Y.; Matsui, H.; Motoyaji, T.; Tanaka, T.; Habuka, N.;Sogabe, S.; Ono, M.; Siedem, C. S.; Tang, T. P.; Gauthier, C.; De Meese, L. A.; Boyd, S. A.; Fukumoto, S. J. Med. Chem. 2011, 54, 8616. 
[12] Zheng K.B., He J., Zhang J. (2008) Synthesis and antitumor activity of N1-acetylamino-(5-alkyl/aryl- 1,3,4-thiadiazole-2yl)-5-fluorouracil derivatives. Chin Chem Lett;19:1281-1284.

[13] Chen, C. J.; Song, B. A.; Yang, S.; Xu, G. F.; Bhadury, P. S.; Jin, L. H.; Hu, D. Y.; Li, Q. Z.; Liu, F.; Xue, W.; Lu, P.; Chen, Z. Bioorg. Med. Chem. 2007, 15, 3981.

[14] Bhawna Sharma, Amita Verma, Sunil Prajapati and Upendra Kumar Sharma. International Journal of Medicinal Chemistry. Volume 2013, Article ID 348948, 16 pages

[15] Yang Hu, Cui-Yun Li, Xiao-Ming Wang, Yong-Hua Yang, and Hai-Liang Zhu. 1,3,4-Thiadiazole: Synthesis, Reactions, and Applications in Medicinal, Agricultural, and Materials Chemistry. Chem. Rev. 2013. dx.doi.org/10.1021/cr400131u

[16] Stefan Remy and Heinz Beck. Molecular and cellular mechanisms of pharmacoresistance in epilepsy. Brain (2006), 129, $18-35$.

[17] Oruc E, Rollas S, Kandemirli F, Shvets N, Dimoglo A (2004) 1, 3, 4-thiadiazole derivatives, synthesis, structure elucidation and structure antituberculosis activity relationship investigation. J Med Chem 47: 6760-6767

[18] Pandeya SN, Raja AS, Stables JP. Synthesis of isatin semicarbazones as novel anticonvulsants- role of hydrogen bonding. J. Pharm Pharm Sci. (2002) 5(3): 266-71

[19] Christopher B. Chapleo, Malcolm Myers, Peter L. Myers, John F. Saville, Alan C. B. Smith, Michael R. Stillings, Ian F. Tulloch, Donald S. Walter, and Anthony P. Welbourn. Substituted 1,3,4-Thiadiazoles with Anticonvulsant Activity. 1. Hydrazines. Journal of Medicinal Chemistry, 1986, Vol. 29, No. 11.

[20] Michael R. Stillings, Anthony P. Welbourn, and Donald S. Walter. Substituted 1,3,4-Thiadiazoles with Anticonvulsant Activity. 2. Aminoalkyl Derivatives. J. Med. Chern. 1986,29, 2280-2284.

[21] Christopher B. Chapleo, Peter L. Myers, Alan C. B. Smith, Ian F. Tulloch, and Donald S. Walter.Substituted 1,3,4Thiadiazoles with Anticonvulsant Activity. 3. Guanidines. J. Med. Chem. 1987,30, 951-954.

[22] Christopher B. Chapleo,Peter L. Myers, Alan C. B. Smith, Michael R. Stillings, Ian F. Tulloch,and Donald S. Walter. Substituted 1,3,4-Thiadiazoles with Anticonvulsant Activity. 4. Amidines.J. Med. Chem. 1988, 31, 7-11.

[23] Hatice N. Dogan, Arzu Duran, Sevim Rollas, Go“ ksel Sener, Meral K. Uysal and Dumrul Gu“ len. Synthesis of New 2,5Disubstituted-1,3,4-thiadiazoles and Preliminary Evaluation of Anticonvulsant and Antimicrobial Activities. Bioorganic \& Medicinal Chemistry10 (2002) 2893-2898.

[24] Archana , V.K. Srivastava, Ashok Kumar. Synthesis of newer thiadiazolyl and thiazolidinonyl quinazolin-4(3H)-ones as potential anticonvulsant agents. European Journal of Medicinal Chemistry 37 (2002) 873-882.

[25] Hatice N. Dogan, Arzu Duran, Sevim Rollas, Go“ ksel Sener, Meral K. Uysal and Dumrul Gu“ len. Synthesis of New 2,5Disubstituted-1,3,4-thiadiazoles and Preliminary Evaluation of Anticonvulsant and Antimicrobial Activities. Bioorganic \& Medicinal Chemistry10 (2002) 2893-2898.

[26] Archana, V. K. Srivastava and Ashok Kumar. Synthesis of some newer derivatives of substituted quinazolinonyl-2oxo/thiobarbituric acid as potent anticonvulsant agents. Bioorganic \& Medicinal Chemistry 12 (2004) 1257-1264.

[27] Marc A. Ilies, Bernard Masereel,b, St_ephanie Rolin, Andrea Scozzafava, Gheorghe Campeanu, Valentin Cimpeanud and Claudiu T. Supuran. Carbonic anhydrase inhibitors: aromatic and heterocyclic sulfonamides incorporating adamantyl moieties with strong anticonvulsant activity. Bioorganic \& Medicinal Chemistry 12 (2004) 2717-2726.

[28] Kamal M. Dawood, Hassan Abdel-Gawad, Eman A. Rageb, Mohey Ellithey and Hanan A. Mohamed. Synthesis, anticonvulsant, and anti-inflammatory evaluation of some new benzotriazole and benzofuran-based heterocycles. Bioorganic \& Medicinal Chemistry 14 (2006) 3672-3680.

[29] Foroumadi A., Sheibani V., Sakhteman A., Rameshk M, Abbasi M., Farazifard R., Tabatabai S.A., Shafiee A. Synthesis and anticonvulsant activity of novel 2-amino-5-[4-chloro-2-(2-chlorophenoxy) phenyl]-1,3,4-thiadiazole derivatives. Daru vol. 15, no. 22007.

[30] Varsha Jatav, Pradeep Mishra, Sushil Kashaw , J.P. Stables . Synthesis and CNS depressant activity of some novel 3-[5substituted 1,3,4-thiadiazole-2-yl]-2-styryl quinazoline-4(3H)-ones. European Journal of Medicinal Chemistry 43 (2008) 135-141.

[31] Varsha Jatav, Pradeep Mishra, Sushil Kashaw, J.P. Stables. CNS depressant and anticonvulsant activities of some novel 3[5-substituted 1,3,4-thiadiazole-2-yl]-2-styryl quinazoline-4(3H)-ones, European Journal of Medicinal Chemistry 43 (2008) $1945-1954$

[32] Asif Husain, Mohammad A. Naseer and Mohammad Sarafroz. Synthesis and anticonvulsant activity of some novel fused heterocyclic 1,2,4-Triazolo-[3,4-b]-1,3,4-Thiadiazole Derivatives. Acta Poloniae Pharmaceutica and Drug Research, Vol. 66 No. 2 pp. 135-140, 2009.

[33] Mohammad Shahar Yar and Mohammad Wasim Akhter. Synthesis and anticonvulsant activity of substituted oxadiazole and thiadiazole derivatives. Acta Poloniae Pharmaceutica n Drug Research, Vol. 66 No. 4 pp. 393-397, 2009

[34] Nadeem Siddiqui, Arpana Rana, Suroor A. Khan, S. Ehtaishamul Haque, M. Faiz Arshad, Sharique Ahmed,Waquar Ahsan. Synthesis and preliminary screening of benzothiazol-2-yl thiadiazole derivatives for anticonvulsant activity. Acta Pharm. 59 (2009) 441-451. 
[35] Priyabrata Pattanayak, Rajesh Sharma ,Prasanta Kumar Sahoo. Synthesis and evaluation of 2-amino-5-sulfanyl-1,3,4thiadiazoles as antidepressant, anxiolytic, and anticonvulsant agents. Med Chem Res (2009) 18:351-361.

[36] Hemlata Kaur, Sunil Kumar, Pinki Vishwakarma, Monica Sharma, K.K. Saxena, Ashok Kumar. Synthesis and antipsychotic and anticonvulsant activity of some new substituted oxa/thiadiazolylazetidinonyl/thiazolidinonylcarbazoles. European Journal of Medicinal Chemistry 45 (2010) 2777-2783.

[37] Harish Rajak, Chinmay Kumar Behera,Rajesh Singh Pawar,Pradeep Kumar Singour And Murli Dhar Kharya. Synthesis and anticonvulsant evaluation of some novel 2,5-disubstituted 1,3,4-thiadiazoles: pharmacophore model studies. Acta Poloniae Pharmaceutica n Drug Research, Vol. 67 No. 5 pp. 503-510, 2010.

[38] Rajesh Sharma, Ganesh Prasad Misra, Jitendra Sainy, Subhash Chandra Chaturvedi. Synthesis and biological evaluation of 2-amino-5-sulfanyl-1,3, 4-thiadiazole derivatives as antidepressant, anxiolytics and anticonvulsant agents, Med Chem Res (2011) 20:245-253.

[39] Nadeem Siddiqui, Waquar Ahsan. Synthesis, anticonvulsant and toxicity screening of thiazolyl-thiadiazole derivatives. Med Chem Res (2011) 20:261-268.

[40] Harish Rajak, Bhupendra S. Thakur, Pramod Kumar, Poonam Parmar, Prabodh Chander Sharma, Ravichandran Veerasamy And Murli Dhar Kharya. Synthesis and antiepileptic activity of some novel semicarbazones containing 1,3,4-Thiadiazole and Quinazoline ring. Acta poloniae pharmaceutica-drug research, Vol. 69 No. 2 pp. 253-261, 2012.

[41] Hemlata Kaur, Sunil Kumar, Archana Chaudhary, Ashok Kumar. Synthesis and biological evaluation of some new substituted benzoxazepine and benzothiazepine as antipsychotic as well as anticonvulsant agents. Arabian Journal of Chemistry (2012) 5, 271-283.

[42] Kikkeri P. Harish, Kikkeri N. Mohana, and Lingappa Mallesha. Synthesis of Pyrazine Substituted 1,3,4-Thiadiazole Derivatives and Their Anticonvulsant Activity. Organic Chemistry International.Volume 2013, Article ID 631723, 8 pages.

[43] Kikkeri P. Harish, Kikkeri N. Mohana, Lingappa Mallesha. Synthesis of indazole substituted-1,3,4-thiadiazoles and their anticonvulsant activity. drug invention today 5 (2 $\left.\begin{array}{lllll}2 & 0 & 1 & 3\end{array}\right)$ 92-99.

[44] S. Botros, Nadia A. Khalil, Bassem H. Naguib, Yara El-Dash. Synthesis and anticonvulsant activity of new phenytoin derivatives. European Journal of Medicinal Chemistry 60 (2013) 57-63.

[45] Mohammad Yusuf, Riaz A. Khan, Maria Khan and Bahar Ahmed. An Interactive Human Carbonic Anhydrase-II (hCAII)Receptor -Pharmacophore Molecular Model \& AntiConvulsant Activity of the Designed and Synthesized 5-Amino1,3,4-Thiadiazole-2-Thiol Conjugated Imine Derivatives. Chem Biol Drug Des 2013; 81: 666-673.

[46] Rajesh Sharma, Yogendra Prasad, Ganesh Prasad Mishra, S. C. Chaturvedi. Some substituted 1,3,4-thiadiazoles: a novel centrally acting agents. Med Chem Res (2014) 23:252-258

[47] K. P. Harish, K. N. Mohana, and L. Mallesha, Synthesis of New 2,5-Disubstituted-1,3,4-Thiadiazole Derivatives and Their in vivo Anticonvulsant Activity. Russian Journal of Bioorganic Chemistry, 2014, Vol. 40, No. 1, pp. 97-105. 